\title{
Cinnabarinic acid-induced stanniocalcin 2 confers cytoprotection against alcohol-induced liver injury
}

Aditya D. Joshi ${ }^{\star}$, Gopal Thinakaran, and Cornelis Elferink

Department of Pharmaceutical Sciences, University of Oklahoma Health Sciences Center, Oklahoma City, OK 73117 (ADJ)

Byrd Alzheimer's Center and Research Institute and Department of Molecular Medicine, University of South Florida, Tampa, FL 33613 (GT)

Department of Pharmacology and Toxicology, University of Texas Medical Branch, Galveston, TX 77555 (CJE) 
Running Title: STC2 protects against alcoholic liver disease

Corresponding Author: * Dr. Aditya D. Joshi, Department of Pharmaceutical Sciences, University of Oklahoma Health Sciences Center, 1110 N. Stonewall Ave., Oklahoma City, Oklahoma 73117, E-mail: aditya-joshi@ouhsc.edu

Number of Text Pages: 45

Number of Tables: 0

Number of Figures: 7

Number of References: 61

Abstract word count: 195

Introduction word count: 595

Discussion word count: 1108

Abbreviations: STC2, stanniocalcin 2; CA, cinnabarinic acid; AhR, aryl hydrocarbon receptor; ER, endoplasmic reticulum; XRE, xenobiotic response element.

Recommended Section: Cellular and Molecular 


\section{ABSTRACT}

We recently identified upregulation of a novel aryl hydrocarbon receptor (AhR) target gene, stanniocalcin 2 (stc2) by an endogenous AhR agonist, cinnabarinic acid (CA). STC2 is a disulfide-linked homodimeric secreted glycoprotein that plays role in various physiological processes including cell metabolism, inflammation, endoplasmic reticulum and oxidative stress, calcium regulation, cell proliferation and apoptosis. Our previous studies have confirmed that CA-induced AhR-dependent STC2 expression was able to confer cytoprotection both in vitro and in vivo in response to injury induced by variety of ER/oxidative insults. Here, we used mouse models of chronic and acute ethanol feeding and demonstrated that upregulation of STC2 by CA was critical for cytoprotection. In STC2 knock-out mice $\left(\mathrm{STC2}^{-/}\right)$, CA failed to protect against both acute as well as chronic-plus-binge ethanol-induced liver injury, whereas re-expression of STC2 in the liver using in vivo gene delivery restored cytoprotection against injury based on measures of apoptosis and serum levels of liver enzymes, underlining STC2's indispensable function in cell survival. In conclusion, the identification of STC2 as an AhR target gene receptive to CA-mediated endogenous AhR signaling and STC2's role in providing cytoprotection against liver injury represents a key finding with potentially significant therapeutic implications. 


\section{SIGNIFICANCE STATEMENT}

We recently identified stanniocalcin 2 (stc2) as a novel AhR target gene regulated by endogenous AhR agonist and tryptophan metabolite, cinnabarinic acid (CA). Here, we showed that CA-induced STC2 expression conferred cytoprotection against apoptosis, steatosis, and liver injury in chronic as well as acute models of ethanol feeding. Therefore, this study will prove instrumental in developing CA as a promising lead compound for future drug development against hepatic diseases. 


\section{INTRODUCTION}

Persistent and excessive hepatocyte apoptosis plays a fundamental role in a plethora of liver ailments, including alcohol-induced diseases (Su et al., 1998; Guicciardi et al., 2013). Therefore, the development of novel intervention strategies that can attenuate excessive apoptosis may provide therapeutics against both acute and chronic hepatic diseases. The aryl hydrocarbon receptor (AhR) has recently been identified as a potential therapeutic target in a variety of liver, oncogenic, immune, and inflammatory diseases; highlighting AhR ligands as attractive candidates with beneficial pharmaceutical properties (Mulero-Navarro and Fernandez-Salguero, 2016). Historically, the AhR has been examined as a modulator of xenobiotic metabolism due to its involvement in the activation of cytochrome P450 1A1 (cyp1a1) expression in response to the classical exogenous ligand 2,3,7,8-tetrachlorodibenzo-p-dioxin (TCDD). In the canonical pathway, agonist binding initiates AhR nuclear translocation, followed by heterodimerization with the AhR nuclear translocator protein (Arnt) and binding to the xenobiotic response elements (XREs, harboring a 5'-GCGTG-3' core motif) in the promoter region of AhR controlled genes (Legraverend et al., 1982; Probst et al., 1993). We recently established that the tryptophan catabolite, cinnabarinic acid $(C A)$, is an endogenous $A h R$ agonist that can regulate expression of a novel AhR target gene, stanniocalcin 2 (stc2) (Harper et al., 2013; Lowe et al., 2014; Joshi et al., 2015). CA treatment promoted direct AhR binding to an enhancer cassette encompassing 8 XREs located within the stc2 promoter (Harper et al., 2013; Joshi et al., 2015; Joshi et al., 2017). Notably, CA does not trigger expression of the canonical AhR target gene cyp1a1 in the liver (Harper et al., 2013; Joshi et al., 2015). Conversely, stc2 is non- 
responsive to exogenous AhR agonists, including TCDD (Harper et al., 2013). These data reveal that CA and TCDD drive mutually exclusive AhR-mediated transcriptional processes in spite of using a core mechanism that involved AhR-Arnt heterodimer interaction with XRE enhancer elements.

STC2 is a secreted, glycosylated, disulfide-linked protein expressed in a wide variety of tissues and is predicted to function in an autocrine and/or paracrine manner (Wagner and Dimattia, 2006; Joshi, 2020). STC2's anti-apoptotic role was first revealed in N2a and PC12 cell lines subjected to thapsigargin- and tunicamycin-stimulated ER stress and hypoxia (Ito et al., 2004). Mechanistically, STC2 has been shown to alter protein kinase RNA-like endoplasmic reticulum kinase (PERK), protein kinase $B(A K T)$, and extracellular-signal-regulated kinase (ERK) signaling during protection against ER and/or oxidative stress-induced apoptosis (Fazio et al., 2011; Kim et al., 2015). Published findings also indicate involvement of STC2 in regulating cellular calcium stores thereby protecting against unfolded proteins response (Zeiger et al., 2011). Additionally, a recent report suggests that STC2 activates STAT3 signaling to ameliorate hepatosteatosis (Zhao et al., 2018). Our laboratory has previously shown that in primary hepatocytes, CA-induced STC2 expression protected cultured cells against apoptosis induced by both ER and oxidative stressors (Joshi et al., 2015). Furthermore, in vivo studies using AhR-positive (AhR floxed) mice and AhR liverspecific conditional knockout mice (AhR CKO) subjected to acute ethanol toxicity demonstrated that CA pretreatment protected the livers against ethanol-induced overt liver injury manifested as hepatocyte apoptosis and microvesicular steatosis in a mechanism that was AhR-dependent (Joshi et al., 2015). 
In the present study, we further examined CA's capacity to protect mice against hepatic injury in models of alcoholic liver disease. Our data strongly suggest that the CA-driven STC2 elevation is responsible for protection against ethanol-induced hepatocyte apoptosis, liver steatosis, and injury in both acute and chronic models of hepatotoxicity. Moreover, the introduction of an STC2 expression construct into STC2 knockout mouse livers using in vivo gene transfections protected animals against hepatic injury following ethanol insult. 


\section{MATERIALS AND METHODS}

Animals and in vivo treatments. Eight to ten-weeks-old STC2 ${ }^{+/+}$and $\mathrm{STC2}^{-/-}$(STC2 knock-out, STC2 KO mice obtained from Dr. Gopal Thinakaran) (Zeiger et al., 2011) female mice, which are more susceptible to both acute and chronic alcohol-induced liver injury than males, were used as per the Institutional Animal Care and Use Committee, University of Texas Medical Branch's guidelines (limuro et al., 1997; Eagon, 2010; Wagnerberger et al., 2013). For chronic alcohol studies, NIAAA 'chronic and binge ethanol feeding model' was utilized (Bertola et al., 2013). Mice were initially fed with control Lieber-DeCarli ad libitum diet (Bio-Serv, Flemington, NJ) for five days, followed by Lieber-Dicarli diet containing $5 \% \mathrm{vol} / \mathrm{vol}$ ethanol (Bio-Serv) for 10 days. The control mouse group had free access to an isocaloric control diet (Bio-Serv) (Bertola et al., 2013). On day 11 , a single dose of ethanol at $6 \mathrm{gm} / \mathrm{kg}$ body weight (binge) or $10.8 \mathrm{gm}$ isocaloric maltose dextrin per $\mathrm{kg}$ of body weight (for the control group), were administered through oral gavage. Mice were euthanized after nine hours by inhalant anesthetic overdose of isoflurane followed by removal of a vital organ as a secondary assurance method. Mice livers were subsequently harvested. For mice in 'control + CA' and 'Ethanol + CA' groups, $12 \mathrm{mg} / \mathrm{kg}$ of CA (dissolved with $2 \%$ DMSO in saline) was administered daily for 11 days via intraperitoneal injections (i.p.). CA was synthesized by Synthetic Organic Chemistry Core at the University of Texas Medical Branch (Joshi et al., 2017). For chronic and binge ethanol feeding studies, mice were housed individually for the measurement of diet and were provided with environmental enrichments to mitigate stress. For acute alcohol model, mice were treated with $6 \mathrm{gm} / \mathrm{kg}$ (body weight) ethanol oral gavage for 12 hr (Zhou et al., 2001; Zhou et al., 2003). For 
'Ethanol + CA' group, mice were pretreated with 12 mg/kg CA via i.p. for $12 \mathrm{hr}$ (Joshi et al., 2015). Twelve hours after CA injection, ethanol was administered. Twelve hours after the ethanol treatment mice were euthanized.

\section{Detection of CA in liver extracts by High Performance Liquid Chromatography /}

Tandem Mass Spectrometry. Livers from different treatment groups collected after chronic and acute ethanol studies were sonicated in $4 \%$ trichloroacetic acid. Liver homogenates were centrifuged at $2200 \times \mathrm{g}$ for $30 \mathrm{~min}$. Pellets were resuspended in 300 $\mu \mathrm{l}$ of acetonitrile. Samples were vortexed and centrifuged at $9000 \times \mathrm{g}$ for $5 \mathrm{~min}$, and 200 $\mu$ l of supernatants were air-dried by speed vacuum centrifuge. The pellets were suspended with $100 \mu \mathrm{l}$ of formic acid and injected into the high-performance liquid chromatography (HPLC). Chromatographic separation was performed at the University of Texas Medical Branch Mass Spectrometry Facility on a reversed-phase column (50 X $2.0 \mathrm{~mm}$; Luna C18, $5 \mu \mathrm{m}, 100-\AA ̊ \AA$ pore size), equipped with a security guard pre-column (Phenomenex, Torrance, CA), containing the same packing material as described previously (Fazio et al., 2012). The mass spectrometry was performed using Orbitrap Fusion (ThermoFisher Scientific, Waltham, MA) at the Mass Spectrometry Facility (University of Texas Medical Branch). The HPLC coupled MS/MS experimental setup and parameters were identical as previously described (Fazio et al., 2012). CA concentrations were measured by establishing a concentration curve using different concentrations of CA, which were dissolved in acetonitrile and processed exactly as the liver samples.

RNA isolation and quantitative reverse transcription - polymerase chain reaction. Total RNA was isolated from liver tissues using TRIzol (ThermoFisher Scientific). First- 
strand cDNA was prepared from total RNA using an oligo(dT) primer (New England Biolabs, Ipwich, MA) and SuperScript II Reverse Transcriptase (ThermoFisher Scientific). Quantitative polymerase chain reaction (qRT-PCR) was performed using ABI 7500 Fast Real-Time PCR system (ThermoFisher Scientific) in the Molecular Genomics Core facility at the University of Texas Medical Branch with oligonucleotide primers for mouse stc2 (forward: GTCGGTGTGATTGTGGAGATGAT and reverse: TCCACATAGGGCTCATGCAG) and mouse cyp1a1 (forward: GCCTAACTCTTCCCTGGATGC and reverse: TCAATGAGGCTGTCTGTGATGTC)

Western blot analysis. Liver extracts were prepared in cell lysis buffer (Cell Signaling Technology, Danvers, MA). SDS-PAGE, transfer to Hybond-P membranes (GE Healthcare Life Sciences, Waukesha, WI) was followed by probing the membranes with custom rabbit polyclonal antibody against STC2 (ProSci Inc., Poway, CA) (Joshi et al., 2015). Cy3 goat anti-rabbit fluorescent secondary antibody (GE Healthcare Life Sciences) was used. Typhoon Trio Variable Mode Imager (GE Healthcare Life Sciences) was used to image Western blots.

Caspase 3 assays. Assays were performed using a caspase 3 assay kit as per the manufacturer's directions (BD Biosciences, San Jose, CA) (Joshi et al., 2015). Briefly, fluorogenic caspase-3 substrate, Ac-DEVD-AFC was added to $50 \mu \mathrm{l}$ liver lysates and incubated at $37^{\circ} \mathrm{C}$ for $1 \mathrm{hr}$. Fluorescence resulting from the cleavage of 7 -amino-4trifluoromethylcoumarin (AFC) was quantified on GloMax Explorer multimode microplate reader (Promega, Madison, WI).

Terminal deoxynucleotidyl transferase dUTP nick end labeling assay. Liver tissues collected after chronic and acute ethanol treatments were processed for cryo-sectioning 
using Leica CM 1900 cryostat (Leica Biosystems, Buffalo Grove, IL). Sections were fixed in 4\% paraformaldehyde for 20 min at room temperature, washed with PBS for 30 min, permeabilized with $0.1 \%$ Triton $\mathrm{X}-100$ and $0.1 \%$ sodium citrate containing permeabilization solution for 2 min at $4^{\circ} \mathrm{C}$. TUNEL reaction mixture provided in the in situ cell death detection kit, TMR red (Millipore Sigma, St. Louis, MO) was added to the permeabilized sections and incubated for $1 \mathrm{hr}$ at $37^{\circ} \mathrm{C}$. Slides were rinsed with PBS and treated with SlowFade Gold with DAPI (TheroFisher Scientific). Axiovert 200 epifluorescence microscope (Zeiss, Thornwood, NY) was utilized to capture the TUNEL positive apoptotic nuclei.

Alanine aminotransferase assay. Serum alanine aminotransferase (ALT) activity was measured using an fluorometric alanine aminotransferase activity assay kit (Abcam, Cambridge, MA) according to the manufacturer's instructions.

H\&E staining. Liver tissues collected after a chronic-plus-binge and acute ethanol treatments were placed in $10 \%$ neutral buffered formalin and submitted to Anatomic Pathology Laboratory at the University of Texas Medical Branch for paraffin embedding, sectioning, and staining with $\mathrm{H} \& \mathrm{E}$.

in vivo delivery of STC2. Mouse STC2 (Horizon - Perkin Elmer, Waltham, MA) was subcloned into a commercially available pLIVE ${ }^{\circledR}$ plasmid (Mirus Bio, Madison, WI). For in vivo delivery of the STC2/pLIVE plasmid into STC2 ${ }^{-/}$mouse liver, we employed in vivo-jet $\mathrm{PEI}^{\circledR}$-Gal (Polyplus Transfection, Illkirch, France) system as per the manufacturer's instructions. For each mouse, $40 \mu \mathrm{g}$ of endotoxin-free STC2/pLIVE was delivered through tail vein injections (Girer et al., 2021). 
Primary hepatocyte isolation and treatments. Hepatocytes from $\mathrm{STC2}^{-/}$mice transfected in vivo with pLIVE (control) and STC2/pLIVE plasmids were isolated using the collagenase perfusion method as previously described (Park et al., 2005). Isolated hepatocytes were plated at a density of $1,000,000$ cells $/ \mathrm{cm}^{2}$ in Williams $E$ medium containing penicillin $(100 \mathrm{U} / \mathrm{ml})$, streptomycin $(100 \mu \mathrm{g} / \mathrm{ml})$, and $5 \%$ fetal bovine serum. Hepatocytes were treated with $100 \mathrm{mM}$ ethanol for $24 \mathrm{hr}$ and subjected to immunofluorescence imaging.

Immunohistochemistry and immunocytochemistry. Livers from $\mathrm{STC2}^{-/-}$mice transfected in vivo with pLIVE and STC2/pLIVE plasmids were paraffin embedded and sectioned at the Anatomic Pathology Laboratory, University of Texas Medical Branch. Moreover, primary hepatocytes isolated from the aforementioned mice were plated on Laboratory-Tel II chamber slides (ThermoFisher Scientific) at a density of 20,000 cells / $1.7 \mathrm{~cm}^{2}$ and subjected to immunocytochemistry. Both tissue sections and primary hepatocytes were fixed with $4 \%$ paraformaldehyde for 30 min at $4^{\circ} \mathrm{C}$, permeabilized with $0.2 \%$ Triton X-100 for 30 min, and blocked with $5 \%$ bovine serum albumin (BSA) for 1 hr. Liver tissue sections were treated with anti-STC2 antibody (ProSci Inc.) and SlowFade Gold with DAPI (TheroFisher Scientific). For primary hepatocytes, slides were co-immunostained with anti-STC2 (ProSci Inc.) and anti-cleaved caspase 3 (Cell Signaling Technologies) antibodies. Tissue sections and cells were incubated with primary antibodies overnight at $4^{\circ} \mathrm{C}$. Secondary antibodies Alexa Fluor 488 and 594 (ThermoFisher Scientific) were used for fluorescent detection using Axiovert 200 epifluorescence microscope (Zeiss). 
Statistical Analysis. Chronic-plus-binge as well as acute ethanol studies performed in this study, were conducted with a predetermined plan. The animal/sample sizes per groups, data acquisition and analysis methods, blinding were preset (Michel et al., 2020). Animal sample size was determined by calculating an effect size based on our previous experiments (Joshi et al., 2015) and by performing power analysis calculations for ANOVA using G*Power statistical suite (Faul et al., 2009) with type I error set at 5\% and type II error at $80 \%$. Sample size used for the current study is consistent with our previously performed in vivo studies (Joshi et al., 2015; Girer et al., 2021). Ethanol and CA treatments in chronic and acute models were performed using appropriate blinding methods. Data were analyzed by a Sigma Plot software (Systat Software, San Jose, CA) using a mixed-effects multivariate ANOVA (MANOVA) model unless noted in the figure legends. Following the overall significant $F$ test from the mixed-effects multivariate ANOVA model, the posthoc multiple comparison tests were performed for the prespecified comparisons adjusted by the Tukey procedure. Data are shown as mean \pm SD. Only if the $p$ value $<0.05$ then the differences between the groups are considered statistically significant. 


\section{RESULTS}

Cinnabarinic acid induces STC2 expression in the mouse model of chronic and binge ethanol feeding. We previously showed that CA-induced AhR-mediated STC2 upregulation confers cytoprotection following injury induced by ER/oxidative stressors (Joshi et al., 2015). The focus of this study is to demonstrate CA-driven STC2 expression can protect against hepatocyte apoptosis, steatosis, and liver injury in both chronic and acute models of ethanol-induced liver disease. We subjected STC2 positive $\left(\mathrm{STC2}^{+/+}\right)$and knockout $\left(\mathrm{STC2}^{-/}\right)$mice to both chronic and acute alcoholinduced liver injury, without and with CA treatment. The chronic-plus-binge ethanol administration protocol, developed at the National Institute on Alcohol Abuse and Alcoholism (NIAAA) of the National Institutes of Health $(\mathrm{NIH})$, represents an animal model which mirrors heavy drinker consumption patterns that triggers a strong neutrophil-mediated liver injury reflective of alcoholic hepatitis (Bertola et al., 2013). The protocol involves an 11-day alcohol feeding paradigm followed by a final ethanol bolus and results in hepatocyte apoptosis, liver injury, inflammation, and fatty liver (Bertola et al., 2013). We measured caloric intake and body weights of $\mathrm{STC2}^{+/+}$and $\mathrm{STC2}^{-/}$mice over the study period. During the acclimatization phase, total caloric intake by $\mathrm{STC2}^{-/}$mice was noticeably less than that of $\mathrm{STC}^{+/+}(\mathrm{Fig} .1 \mathrm{~A})$, although caloric intake in ethanol-fed STC2 ${ }^{-/}$mice did transiently increase-that is, between days 6-10. 
Overall, however, caloric intake by the $\mathrm{STC2}^{++}$and $\mathrm{STC2}^{-/-}$mice during the 11-day ethanol feeding period were comparable (Fig. 1A). Additionally, body weights and weight gain between the various treatment groups in $\mathrm{STC}^{+/+}$and $\mathrm{STC}^{-/-}$mice were similar (Fig. 1B). In this study, CA and vehicle (control) were administered daily by i.p. injections, and the serum and liver CA concentrations were measured using HPLC/MSMS (Fazio et al., 2012). As expected, there was an increase in the liver (Fig. 1C) and serum (Fig. 1D) CA in the CA treatment groups. Despite the substantial increase in serum CA, the basal liver CA level in control mice $(\approx 10 \mathrm{pg} / \mathrm{mg})$ increased by only about $50 \%(\approx 15 \mathrm{pg} / \mathrm{mg})$ following daily CA administration, suggesting that liver CA levels are tightly regulated. These data closely approximate previous CA measurements in rat livers which ranged from 7 to $10 \mathrm{pg} / \mathrm{mg}$ (Fazio et al., 2012). The increased CA concentration in $\mathrm{STC2}^{+/+}$mice is associated with $\mathrm{a} \approx 3$-fold induction of liver stc2 expression (Fig. 1E) and absent in the $\mathrm{STC}^{-/}$mice (Fig. 1F). Immunoblotting confirmed that CA-induced stc2 mRNA elevation is complemented by increased protein expression (Fig. 1G). These data also demonstrate that CA-induced AhR activation of stc2 is not reflected in a comparable induction of cyp1a1, consistent with the previously shown agonist specificity (Fig. 1E and F) (Joshi et al., 2015).

Cinnabarinic acid protects against chronic ethanol-induced apoptosis. We next assessed CA's ability to protect against hepatocyte apoptosis in $\mathrm{STC2}^{+/+}$and $\mathrm{STC2}^{-/-}$ mice subjected to a chronic and binge ethanol diet (Bertola et al., 2013). We did not observe any overt adverse phenotypic changes in both strains due to alcohol and/or CA administration. Caspase 3 assay demonstrated that CA-treatment protected $\mathrm{STC2}^{+/+}$ mouse livers from chronic ethanol-induced cell death (Fig. 2A). In contrast, CA- 
mediated cytoprotection was not seen in the livers isolated from STC2 $2^{-/}$mice (Fig. 2A). TUNEL analysis performed on liver sections from STC2 ${ }^{+/+}$and STC2 $2^{-/}$mice corroborated these findings (Fig. 2B). Ethanol-induced liver apoptosis was markedly attenuated in CA-treated $\mathrm{STC2}^{+/+}$mice only. Quantitation of the TUNEL results reveal a CAdependent 4-fold reduction in apoptosis in $\mathrm{STC}^{+/+}$mice not observed in the $\mathrm{STC}^{-/-}$mice (Fig. 2C). These data complement our previous findings in cultured primary hepatocytes (Joshi et al., 2015), and highlight the physiological importance of STC2 in mitigating tissue injury by hepatotoxins (Joshi, 2020). In a separate measure of liver injury, serum alanine transaminase (ALT) levels established that chronic ethanol feeding resulted in significant liver damage that was suppressed by CA only in STC2 ${ }^{+/+}$ mice (Fig. 3A). Histological evaluation confirmed that ethanol feeding induced pronounced steatosis consistent with alcoholic liver disease, which was preventable in CA-treated $\mathrm{STC2}^{+/+}$mice, but not in $\mathrm{STC2}^{-/-}$mice (Fig. 3B). The STC2 status did not noticeably affect liver histology in the control mice or those treated with CA alone.

Cinnabarinic acid-driven STC2 expression provides hepatoprotection against acute alcohol treatment. Binge drinking constitutes a significant health concern which is responsible for numerous deaths annually (Crabb et al., 2020). Hence, the potential for CA to protect the liver against acute alcohol hepatotoxicity was examined in STC2 ${ }^{+/+}$ and $\mathrm{STC2}^{-/}$mice upon an administration of a single oral dose of $6 \mathrm{mg} / \mathrm{kg}$ ethanol for 12 hr, in the presence or absence of CA (Zhou 2001). A significant elevation in CA concentration was observed in the liver (Fig. 4A) and serum (Fig. 4B) of CA-pretreated $\mathrm{STC2}^{+/+}$animals. The CA concentrations analyzed in various acute treatment groups of $\mathrm{STC2}^{-/-}$mice were similar to that of $\mathrm{STC2}^{+/+}$(data not shown). Moreover, the CA 
concentration detected in the liver and serum approximated the values observed following daily administration in the chronic ethanol feeding study (Fig. 1). Accordingly, induction of liver stc2 mRNA was similar ( $\approx 3$-fold) in the binge-fed $\mathrm{STC2}^{+/+}$mice (Fig. 4C), while absent in the STC2 ${ }^{-/}$mice (Fig. 4D). Assessment of liver apoptosis revealed that CA treatment conferred cytoprotection in an STC2-dependent manner in the acute drinking model (Fig. 5A, B and C), reminiscent of the findings obtained in the chronicplus-binge drinking paradigm. Serum ALT assay likewise indicated attenuation of acute ethanol-induced liver injury upon CA pretreatment in the STC2 ${ }^{+/+}$animals, but not in the $\mathrm{STC2}^{-/}$mice (Fig. 5D). These data indicate that CA-induced expression of STC2 confers protection against both acute and chronic ethanol exposures.

\section{STC2 promotes cytoprotection against ethanol-induced hepatotoxicity.}

Reconstitution of STC2 expression in STC2 ${ }^{-/}$knockout mouse livers involved using nanopolyplexes to direct plasmid DNA delivery (Lungwitz et al., 2005; Girer et al., 2021). Twenty-four hours after in vivo transfection of STC2/pLIVE plasmid using in vivo-jetPEI-Gal, stc2 mRNA expression was readily detectable (Fig. 6A), as was STC2 protein expression (Fig. 6B). Immunohistochemistry revealed that STC2 expression predominated around the portal triads and extended into the acini (Fig. 6C). It is noteworthy that expression remained immunologically detectable for at least 21 days (Girer et al., 2021).

In order to verify that STC2 expression conferred in vivo cytoprotection, STC2 ${ }^{-1}$ mice were transfected with STC2/pLIVE plasmid $24 \mathrm{hr}$ prior to treatment with $6 \mathrm{gm} / \mathrm{kg}$ of ethanol via oral gavage for $12 \mathrm{hr}$. Caspase-3 activity measured in liver lysates showed that introduction of STC2 protected livers from ethanol-induced apoptosis to a degree 
observed in CA-treated wild-type mice (Fig. 5A). STC2 ${ }^{-/-}$mice transfected with the empty pLIVE vector exhibited elevated levels of apoptosis similar to untransfected livers (Fig. 7A). Furthermore, primary hepatocytes isolated from in vivo transfected mice and cultured in the presence of $100 \mathrm{mM}$ ethanol for $24 \mathrm{hr}$ revealed that staining for cleaved caspase 3 and STC2 were mutually exclusive (Fig. 7B). These data indicate that cytoprotection against ethanol-induced injury correlated directly with STC2 expression. Finally, serum ALT levels corroborated the caspase 3 findings indicating that liver damage by ethanol was markedly diminished in the STC2 ${ }^{-/}$mice expressing the STC2 transgene (Fig. 7C). 


\section{DISCUSSION}

Excessive alcohol use is a global crisis contributing to around 3 million deaths annually (Iranpour and Nakhaee, 2019). Alcoholic liver disease is one of the most significant clinical manifestation of alcohol abuse that encompasses steatosis (fatty liver), alcoholic hepatitis (inflammation and fibrosis) and cirrhosis (sclerosis) (Subramaniyan et al., 2021). Almost $90 \%$ of all heavy drinkers develop fatty livers, 15 to $20 \%$ of patients with alcoholic fatty liver disease will develop alcoholic hepatitis, and about 20 to $50 \%$ of this population will ultimately progress to cirrhosis (Mann et al., 2003; Osna et al., 2017; Zhu et al., 2017; Crabb et al., 2020). The major pathological causes of alcoholic liver diseases are oxidative and endoplasmic reticulum stressinduced apoptosis, necrosis, inflammation, metabolic changes, and aldehyde toxicity (Nanji, 1998; Casey et al., 2001; Ishii et al., 2003; Subramaniyan et al., 2021). In healthy livers, primary hepatocyte apoptosis is a rare event, but the alcoholic liver disease is associated with significant hepatocyte death (Benedetti et al., 1988; Goldin et al., 1993; Krammer, 1996; Sodeman et al., 2000; Ribeiro et al., 2004; Park et al., 2005; Madesh et al., 2009). Additionally, in vivo experiments indicate that inhibiting hepatocyte apoptosis lessens alcohol-induced liver injury (Wang et al., 2016; Zhu et al., 2017). The severity of alcohol-induced liver disease is a function of the amount and duration of 
alcohol consumption (Mann et al., 2003; Askgaard et al., 2015). Long-term alcohol consumption patterns in the population often contain relative self-restrain from drinking followed by binges of heavy alcohol consumption (i.e., chronic episodic binge). Consequently, experimental models that effectively mimic human drinking patterns including the severity and span of alcohol-induced liver damage in humans are essential for the identification of mechanisms that prevent hepatocyte apoptosis, and may prove instrumental in the development of therapeutic strategies targeting alcoholic liver disease (Lamas-Paz et al., 2018). The current study provides compelling evidence that the tryptophan metabolite and known endogenous AhR agonist, CA facilitates cytoprotection against hepatocyte apoptosis, steatosis, and liver injury in both acute and chronic models of alcohol-induced hepatotoxicity.

Conventionally, AhR was studied within the context of toxicity in response to various expgenous agonists which are persistant environmental pollutants (Nebert and Gelboin, 1968b; Nebert and Gelboin, 1968a; Hankinson, 1979; Hankinson, 1980; Legraverend et al., 1982; Denison et al., 2002). However, recently diverse AhR ligands with beneficial pharmaceutical properties have been identified, which include the selective AhR modulators (SAhRMs) (Jin et al., 2012), StemRegenin 1 (Boitano et al., 2010), bilirubin (Kerkvliet et al., 2002), 2-(1'H-indole-3'-carbonyl)-thiazole-4-carboxylic acid methyl ester (Abron et al., 2018), indole-3-carbinol and indolo[3,2b]carbazole (Bjeldanes et al., 1991), and flavonoids (Kawai et al., 2007; Benavente-Garcia and Castillo, 2008). CA, a byproduct of the kyneurine pathway of tryptophan catabolism was identified as an AhR agonist that was effective in inducing IL22 expression in T lymphocytes (Lowe et al., 2014). First observation of CA's protective role emerged from 
cultured cortical cells, where CA treatment protected neuronal death against 1-methyl-4phenyl-1,2,3,6- tetrahydropyridine toxicity (Fazio et al., 2012). Systemic administration of CA (0.1 to $10 \mathrm{mg} / \mathrm{kg}$ ) also provided protection against experimental autoimmune encephalomyelitis, a model of multiple sclerosis in mice (Fazio et al., 2012). Previous work by our group indicated CA-driven protection against thapsigargin, hydrogen peroxide, and ethanol induced apoptosis in mouse primary hepatocytes (Joshi et al., 2015). Furthermore, in vivo studies using AhR floxed (control) and liver-specific AhR conditional knockout mice demonstrated that the CA treatment attenuated acute ethanol-induced apoptosis, steatosis and injury in an AhR-dependent manner (Joshi et al., 2015).

The findings reported here demonstrate that the CA-activated AhR confers hepatic protection in response to both acute and chronic alcohol-induced injury through a mechanism that requires STC2 induction and function. Previous dose-response studies established that administration of $12 \mathrm{mg} / \mathrm{kg} \mathrm{CA}$ to wild-type C57BL/6 mice maximally induced STC2 by 24 hours, but that STC2 expression was transient, returning to near basal levels within 48 hours (Joshi et al., 2015; Patil et al., 2021). Hence, sustained STC2 expression needed to protect mice in the chronic alcohol studies necessitated daily CA administration. Therefore, from a clinically relevant therapeutic standpoint, understanding tryptophan catabolism and endogenous CA production warrant further investigation. This study exclusively validated that the AhRmediated CA-induced STC2 expression is critical for cytoprotection against alcoholinduced hepatocyte apoptosis and subsequent liver damage. We utilized a novel in vivo gene delivery methodology using a polymer-based transfection reagent (jetPEI-Gal) to 
introduce STC2 into liver cells (Fig. 6). The reagent is conjugated to galactoside and is engineered to facilitate plasmid delivery into cells expressing galactose-specific membrane lectins, such as hepatocytes bearing the asialoglycoprotein receptors or $\mathrm{N}$ acetylgalactosamine receptors (Nickerson and Colledge, 2004; Xia et al., 2012; Girer et al., 2021). In vivo transfection of STC2 was able to confer protection against alcoholinduced apoptosis and liver injury (Fig. 7) - strongly implicating STC2 as a critical downstream mediator of AhR regulated anti-apoptotic signaling.

STC2 is known to regulate various biological functions, including tumorigenesis, cell metabolism, cellular calcium homeostasis, cell proliferation, and apoptosis (Wagner and Dimattia, 2006; Joshi, 2020). Overexpression of STC2 was able to attenuate thapsigargin-induced apoptosis in N2a neuroblastoma cells (Ito et al., 2004). Subsequent experiments performed in the mouse model of cerulein-induced pancreatitis indicated that STC2 altered the PERK signaling pathway, specifically phosphorylation of PERK and downstream ATF4 signaling to attenuate acinar cell apoptosis and pancreatic injury (Fazio et al., 2011). Kim et al. showed that activation of phospho-Akt and phospho-ERK1/2 by STC2 induces cell cycle regulators and concomitantly protects against hydrogen peroxide-induced cell dealth (Kim et al., 2015). In the current study, STC2 ${ }^{-/}$mice exhibited increased hepatocyte apoptosis compared with their $\mathrm{STC2}^{+++}$counterparts in response to both chronic and acute ethanol tratements - strongly suggesting significant physiolgoical role of STC2 in cytoprotection irrespective of exogenous CA treatment (Fig. 2 and 5). Distinct from its documented anti-apoptotic role, STC2 activates STAT3 signaling to alleviate hepatosteatosis (Zhao et al., 2018). In high fat diet-fed mice, STC2 induced STAT3 signaling downregulated 
expression of lipogenic - SREBP1c, FASN, ACC1, and SCD1 genes, thereby dramatically inhibiting palmitate-induced cellular triglyceride deposition and ameliorating hepatosteatosis (Zhao et al., 2018). Therefore, STC2 may modulate multiple molecular signaling pathways contributing to cell suirvival especially in response to ethanolinduced hepatotoxicity. However, future mechanistic studies directed towards understaing role of STC2 in necrosis, oxidative stress and inflammation are needed.

In summary, this study confirmed that the endogenous AhR agonist, CA, bestowed cytoprotection in both chronic and acute ethanol-induced hepatotoxicity models. Moreover, the recently identified AhR target gene STC2 was responsible for the CA-induced AhR-mediated cytoprotection. In conclusion, the observations described in this report establish the AhR-STC2 signaling axis as an attractive target and CA as a promising lead compound for the development of future therapeutics to ameliorate the effects of prevalent hepatotoxins. 


\section{AUTHORSHIP CONTRIBUTIONS}

Participated in research design: Joshi

Conducted experiments: Joshi

Contributed new reagents or analytic tools: Thinakaran

Performed data analysis: Joshi and Elferink

Wrote or contributed to the writing of the manuscript: Joshi, Thinakaran and Elferink 


\section{REFERENCES}

Abron JD, Singh NP, Mishra MK, Price RL, Nagarkatti M, Nagarkatti PS and Singh UP (2018) An endogenous aryl hydrocarbon receptor ligand, ITE, induces regulatory T cells and ameliorates experimental colitis. Am J Physiol Gastrointest Liver Physio/ 315:G220-G230.

Askgaard G, Gronbaek M, Kjaer MS, Tjonneland A and Tolstrup JS (2015) Alcohol drinking pattern and risk of alcoholic liver cirrhosis: a prospective cohort study. Journal of hepatology 62:1061-1067.

Benavente-Garcia O and Castillo J (2008) Update on uses and properties of citrus flavonoids: new findings in anticancer, cardiovascular, and anti-inflammatory activity. Journal of agricultural and food chemistry 56:6185-6205.

Benedetti A, Brunelli E, Risicato R, Cilluffo T, Jezequel AM and Orlandi F (1988) Subcellular changes and apoptosis induced by ethanol in rat liver. Journal of hepatology 6:137-143.

Bertola A, Mathews S, Ki SH, Wang H and Gao B (2013) Mouse model of chronic and binge ethanol feeding (the NIAAA model). Nat Protoc 8:627-637.

Bjeldanes LF, Kim JY, Grose KR, Bartholomew JC and Bradfield CA (1991) Aromatic hydrocarbon responsiveness-receptor agonists generated from indole-3-carbinol in vitro and in vivo: comparisons with 2,3,7,8-tetrachlorodibenzo-p-dioxin. Proceedings of the National Academy of Sciences of the United States of America 88:9543-9547.

Boitano AE, Wang J, Romeo R, Bouchez LC, Parker AE, Sutton SE, Walker JR, Flaveny CA, Perdew GH, Denison MS, Schultz PG and Cooke MP (2010) Aryl 
hydrocarbon receptor antagonists promote the expansion of human hematopoietic stem cells. Science 329:1345-1348.

Casey CA, Nanji A, Cederbaum Al, Adachi M and Takahashi T (2001) Alcoholic liver disease and apoptosis. Alcohol Clin Exp Res 25:49S-53S.

Crabb DW, Im GY, Szabo G, Mellinger JL and Lucey MR (2020) Diagnosis and Treatment of Alcohol-Associated Liver Diseases: 2019 Practice Guidance From the American Association for the Study of Liver Diseases. Hepatology 71:306333.

Denison MS, Pandini A, Nagy SR, Baldwin EP and Bonati L (2002) Ligand binding and activation of the Ah receptor. Chem Biol Interact 141:3-24.

Eagon PK (2010) Alcoholic liver injury: influence of gender and hormones. World journal of gastroenterology : WJG 16:1377-1384.

Faul F, Erdfelder E, Buchner A and Lang AG (2009) Statistical power analyses using G*Power 3.1: tests for correlation and regression analyses. Behavior research methods 41:1149-1160.

Fazio EN, Dimattia GE, Chadi SA, Kernohan KD and Pin CL (2011) Stanniocalcin 2 alters PERK signalling and reduces cellular injury during cerulein induced pancreatitis in mice. BMC cell biology 12:17.

Fazio F, Lionetto L, Molinaro G, Bertrand HO, Acher F, Ngomba RT, Notartomaso S, Curini M, Rosati O, Scarselli P, Di Marco R, Battaglia G, Bruno V, Simmaco M, Pin JP, Nicoletti F and Goudet C (2012) Cinnabarinic acid, an endogenous metabolite of the kynurenine pathway, activates type 4 metabotropic glutamate receptors. Molecular pharmacology 81:643-656. 
Girer NG, Rontoyanni VG, Joshi A, Patrikeev I, Murton AJ, Porter C, Motamedi M and Elferink CJ (2021) Liver-Specific Nonviral Gene Delivery of Fibroblast Growth Factor 21 Protein Expression in Mice Regulates Body Mass and White/Brown Fat Respiration. The Journal of pharmacology and experimental therapeutics 378:157-165.

Goldin RD, Hunt NC, Clark J and Wickramasinghe SN (1993) Apoptotic bodies in a murine model of alcoholic liver disease: reversibility of ethanol-induced changes. J Pathol 171:73-76.

Guicciardi ME, Malhi H, Mott JL and Gores GJ (2013) Apoptosis and necrosis in the liver. Compr Physio/ 3:977-1010.

Hankinson O (1979) Single-step selection of clones of a mouse hepatoma line deficient in aryl hydrocarbon hydroxylase. Proceedings of the National Academy of Sciences of the United States of America 76:373-376.

Hankinson O (1980) Unstable aryl hydrocarbon hydroxylase-deficient variants of a rat hepatoma line. Somatic Cell Genet 6:751-767.

Harper TA, Jr., Joshi AD and Elferink CJ (2013) Identification of stanniocalcin 2 as a novel aryl hydrocarbon receptor target gene. The Journal of pharmacology and experimental therapeutics 344:579-588.

limuro Y, Frankenberg MV, Arteel GE, Bradford BU, Wall CA and Thurman RG (1997) Female rats exhibit greater susceptibility to early alcohol-induced liver injury than males. The American journal of physiology 272:G1186-1194.

Iranpour A and Nakhaee N (2019) A Review of Alcohol-Related Harms: A Recent Update. Addict Health 11:129-137. 
Ishii H, Adachi M, Fernandez-Checa JC, Cederbaum AI, Deaciuc IV and Nanji AA (2003) Role of apoptosis in alcoholic liver injury. Alcohol Clin Exp Res 27:12071212.

Ito D, Walker JR, Thompson CS, Moroz I, Lin W, Veselits ML, Hakim AM, Fienberg AA and Thinakaran G (2004) Characterization of stanniocalcin 2, a novel target of the mammalian unfolded protein response with cytoprotective properties. Molecular and cellular biology 24:9456-9469.

Jin UH, Lee SO and Safe S (2012) Aryl hydrocarbon receptor (AHR)-active pharmaceuticals are selective AHR modulators in MDA-MB-468 and BT474 breast cancer cells. The Journal of pharmacology and experimental therapeutics 343:333-341.

Joshi AD (2020) New Insights Into Physiological and Pathophysiological Functions of Stanniocalcin 2. Front Endocrinol (Lausanne) 11:172.

Joshi AD, Carter DE, Harper TA, Jr. and Elferink CJ (2015) Aryl hydrocarbon receptordependent stanniocalcin 2 induction by cinnabarinic acid provides cytoprotection against endoplasmic reticulum and oxidative stress. The Journal of pharmacology and experimental therapeutics 353:201-212.

Joshi AD, Hossain E and Elferink CJ (2017) Epigenetic Regulation by Agonist-Specific Aryl Hydrocarbon Receptor Recruitment of Metastasis-Associated Protein 2 Selectively Induces Stanniocalcin 2 Expression. Molecular pharmacology 92:366374. 
Kawai M, Hirano T, Higa S, Arimitsu J, Maruta M, Kuwahara Y, Ohkawara T, Hagihara K, Yamadori T, Shima Y, Ogata A, Kawase I and Tanaka T (2007) Flavonoids and related compounds as anti-allergic substances. Allergol Int 56:113-123.

Kerkvliet NI, Shepherd DM and Baecher-Steppan L (2002) T lymphocytes are direct, aryl hydrocarbon receptor (AhR)-dependent targets of 2,3,7,8tetrachlorodibenzo-p-dioxin (TCDD): AhR expression in both CD4+ and CD8+ T cells is necessary for full suppression of a cytotoxic T lymphocyte response by TCDD. Toxicology and applied pharmacology 185:146-152.

Kim PH, Na SS, Lee B, Kim JH and Cho JY (2015) Stanniocalcin 2 enhances mesenchymal stem cell survival by suppressing oxidative stress. BMB Rep 48:702-707.

Krammer PH (1996) The CD95(APO-1/Fas) receptor/ligand system: death signals and diseases. Cell death and differentiation 3:159-160.

Lamas-Paz A, Hao F, Nelson LJ, Vazquez MT, Canals S, Gomez Del Moral M, Martinez-Naves E, Nevzorova YA and Cubero FJ (2018) Alcoholic liver disease: Utility of animal models. World journal of gastroenterology : WJG 24:5063-5075.

Legraverend C, Hannah RR, Eisen HJ, Owens IS, Nebert DW and Hankinson O (1982) Regulatory gene product of the Ah locus. Characterization of receptor mutants among mouse hepatoma clones. The Journal of biological chemistry 257:64026407.

Lowe MM, Mold JE, Kanwar B, Huang Y, Louie A, Pollastri MP, Wang C, Patel G, Franks DG, Schlezinger J, Sherr DH, Silverstone AE, Hahn ME and McCune JM 
(2014) Identification of cinnabarinic acid as a novel endogenous aryl hydrocarbon receptor ligand that drives IL-22 production. PloS one $9: \mathrm{e} 87877$.

Lungwitz U, Breunig M, Blunk T and Gopferich A (2005) Polyethylenimine-based nonviral gene delivery systems. Eur J Pharm Biopharm 60:247-266.

Madesh M, Zong WX, Hawkins BJ, Ramasamy S, Venkatachalam T, Mukhopadhyay P, Doonan PJ, Irrinki KM, Rajesh M, Pacher P and Thompson CB (2009) Execution of superoxide-induced cell death by the proapoptotic Bcl-2-related proteins Bid and Bak. Molecular and cellular biology 29:3099-3112.

Mann RE, Smart RG and Govoni R (2003) The epidemiology of alcoholic liver disease. Alcohol Res Health 27:209-219.

Michel MC, Murphy TJ and Motulsky HJ (2020) New Author Guidelines for Displaying Data and Reporting Data Analysis and Statistical Methods in Experimental Biology. The Journal of pharmacology and experimental therapeutics 372:136147.

Mulero-Navarro S and Fernandez-Salguero PM (2016) New Trends in Aryl Hydrocarbon Receptor Biology. Front Cell Dev Biol 4:45.

Nanji AA (1998) Apoptosis and alcoholic liver disease. Semin Liver Dis 18:187-190.

Nebert DW and Gelboin HV (1968a) Substrate-inducible microsomal aryl hydroxylase in mammalian cell culture. I. Assay and properties of induced enzyme. The Journal of biological chemistry 243:6242-6249.

Nebert DW and Gelboin HV (1968b) Substrate-inducible microsomal aryl hydroxylase in mammalian cell culture. II. Cellular responses during enzyme induction. The Journal of biological chemistry 243:6250-6261. 
Nickerson HD and Colledge WH (2004) A LacZ-based transgenic mouse for detection of somatic gene repair events in vivo. Gene Ther 11:1351-1357.

Osna NA, Donohue TM, Jr. and Kharbanda KK (2017) Alcoholic Liver Disease: Pathogenesis and Current Management. Alcohol Res 38:147-161.

Park KT, Mitchell KA, Huang G and Elferink CJ (2005) The aryl hydrocarbon receptor predisposes hepatocytes to Fas-mediated apoptosis. Molecular pharmacology 67:612-622.

Patil NY, Tang H, Rus I, Zhang K and Joshi AD (2021) Decoding cinnabarinic acid specific stanniocalcin 2 induction by aryl hydrocarbon receptor. Molecular pharmacology.

Probst MR, Reisz-Porszasz S, Agbunag RV, Ong MS and Hankinson O (1993) Role of the aryl hydrocarbon receptor nuclear translocator protein in aryl hydrocarbon (dioxin) receptor action. Molecular pharmacology 44:511-518.

Ribeiro PS, Cortez-Pinto H, Sola S, Castro RE, Ramalho RM, Baptista A, Moura MC, Camilo ME and Rodrigues CM (2004) Hepatocyte apoptosis, expression of death receptors, and activation of NF-kappaB in the liver of nonalcoholic and alcoholic steatohepatitis patients. The American journal of gastroenterology 99:1708-1717.

Sodeman T, Bronk SF, Roberts PJ, Miyoshi H and Gores GJ (2000) Bile salts mediate hepatocyte apoptosis by increasing cell surface trafficking of Fas. Am J Physiol Gastrointest Liver Physiol 278:G992-999.

Su GL, Rahemtulla A, Thomas P, Klein RD, Wang SC and Nanji AA (1998) CD14 and lipopolysaccharide binding protein expression in a rat model of alcoholic liver disease. The American journal of pathology 152:841-849. 
Subramaniyan V, Chakravarthi S, Jegasothy R, Seng WY, Fuloria NK, Fuloria S, Hazarika I and Das A (2021) Alcohol-associated liver disease: A review on its pathophysiology, diagnosis and drug therapy. Toxicol Rep 8:376-385.

Wagner GF and Dimattia GE (2006) The stanniocalcin family of proteins. J Exp Zool A Comp Exp Bio/305:769-780.

Wagnerberger S, Fiederlein L, Kanuri G, Stahl C, Millonig G, Mueller S, Bischoff SC and Bergheim I (2013) Sex-specific differences in the development of acute alcoholinduced liver steatosis in mice. Alcohol Alcohol 48:648-656.

Wang S, Pacher P, De Lisle RC, Huang H and Ding WX (2016) A Mechanistic Review of Cell Death in Alcohol-Induced Liver Injury. Alcohol Clin Exp Res 40:12151223.

Xia YJ, Zeng D, Xia LM, Yu F, Lin HH, Zhou L, Tian DA and Liu M (2012) Role of monokine induced by interferon-gamma in liver injury induced by hepatitis B virus in mice. J Viral Hepat 19:509-518.

Zeiger W, Ito D, Swetlik C, Oh-hora M, Villereal ML and Thinakaran G (2011) Stanniocalcin 2 is a negative modulator of store-operated calcium entry. Molecular and cellular biology 31:3710-3722.

Zhao J, Jiao Y, Song Y, Liu J, Li X, Zhang H, Yang J and Lu Y (2018) Stanniocalcin 2 Ameliorates Hepatosteatosis Through Activation of STAT3 Signaling. Frontiers in physiology 9:873.

Zhou Z, Sun X and Kang YJ (2001) Ethanol-induced apoptosis in mouse liver: Fas- and cytochrome c-mediated caspase-3 activation pathway. The American journal of pathology 159:329-338. 
Zhou Z, Wang L, Song Z, Lambert JC, McClain CJ and Kang YJ (2003) A critical involvement of oxidative stress in acute alcohol-induced hepatic TNF-alpha production. The American journal of pathology 163:1137-1146.

Zhu M, Zhou X and Zhao J (2017) Quercetin prevents alcohol-induced liver injury through targeting of PI3K/Akt/nuclear factor-kappaB and STAT3 signaling pathway. Experimental and therapeutic medicine 14:6169-6175.

\section{FOOTNOTES}

This work was supported by the National Institutes of Health National Institute of Diabetes and Digestive and Kidney Diseases [grant R01DK122028 to A.D.J], National Institute on Aging [grants RF1AG054223 and RF1AG056061 to G.T.], and National Institutes of Environmental Health Sciences [grants R01ES026874 and P30ES030285 to C.J.E.]. The authors report no conflict of interest. 


\section{FIGURE LEGENDS}

Figure 1. CA upregulates STC2 expression. (A) $\mathrm{STC}^{+/+}$and $\mathrm{STC2}^{-/-}$mice were placed in individual cages and subjected to chronic-plus-binge model of ethanol feeding (the NIAAA model). Lieber-Dicarli diet containing 5\% (vol/vol) ethanol and isocaloric control diet were measured daily ( $n=4$ mice per treatment group). (B) Body weight of $\mathrm{STC2}^{+/+}$and $\mathrm{STC2}^{-/}$mice in various groups were monitored for 16 days $(\mathrm{n}=4)$. HPLC/MS-MS detection of cinnabarinic acid concentration in (C) liver and (D) serum of control and ethanol-treated $\mathrm{STC}^{+/+}$mice $( \pm \mathrm{CA})$. Data are represented as mean $\pm \mathrm{SD}$ from four mice in each treatment group. ${ }^{*} p<0.05$, difference compared to control and ethanol only groups. (E) Quantitative RT-PCR was conducted on RNA isolated from livers of $\mathrm{STC}^{+/+}$mice in various treatment groups to detect stc2 and cyp1a1 RNA expression and normalized to $18 \mathrm{~s}$ rRNA. ${ }^{*} \mathrm{P}<0.05$ compared to control, $\mathrm{n}=4$ mice in each group. (F) Quantitative RT-PCR was performed on liver RNA isolated from STC2 ${ }^{-/}$ mice. Data are represented as mean \pm SD from four mice in each group. (G) Western blotting on total liver lysates was used to detect STC2 protein expression. Actin was utilized as a loading control. Representative image is shown $(n=3)$.

Figure 2. CA protects against chronic ethanol-induced apoptosis. (A) $\mathrm{STC}^{+/+}$and $\mathrm{STC2}^{-/}$mice were treated with chronic and binge regimen of alcohol with daily i.p. administration of CA (12 mg/kg) or vehicle (Control). Liver lysates were subjected to fluorometric caspase 3 assays. The results are shown as the mean \pm SD from four independent experiments (four mice in each treatment group, * represents a statistically significant difference between ethanol-treated and ethanol + CA treated samples). Data 
are normalized to caspase activity in the control group. (B) Liver sections from control, control + CA, ethanol, and ethanol + CA groups were fixed with paraformaldehyde. TMR-red TUNEL reaction mixture labelled apoptotic nuclei (red) whereas DAPI stained all nuclei (blue). Images were acquired using Axiovert 200 epifluorescence microscope (Zeiss). (C) Quantitation of apoptosis was from 4 independent STC2 ${ }^{+/+}$and STC2 ${ }^{-/}$mice in each treatment group and performed by counting TUNEL positive nuclei as a percentage of total nuclei in 8 random fields. ${ }^{*} p<0.05$ difference between ethanol and ethanol + CA treatment groups. Data represented as mean \pm SD.

Figure 3. CA protects against chronic alcohol-mediated hepatotoxicity. (A) ALT enzyme levels were measured in serum collected from chronic and binge ethanol-fed $\mathrm{STC2}^{+/+}$and $\mathrm{STC2}^{-/-}$mice. Data are represented as mean $\pm \mathrm{SD} .{ }^{*}$ indicates a statistically significant difference between ethanol and ethanol + CA treatments $(p<0.05)$. (B) H \& E staining of liver sections from $\mathrm{STC2}^{+/+}$and $\mathrm{STC2}^{-/-}$mice fed with chronic-plus-binge ethanol diet as described in the Figure 1 legend. Representative images are shown for each of the treatments $(n=4)$.

Figure 4. Quantitation of CA concentration and stc2 message in an acute model of ethanol-induced hepatotoxicity. STC2 ${ }^{+/+}$and $\mathrm{STC}^{-/-}$mice were treated with saline (control) for $12 \mathrm{hr}, 12 \mathrm{mg} / \mathrm{kg} \mathrm{CA}$ for $12 \mathrm{hr}, 6 \mathrm{gm} / \mathrm{kg}$ ethanol oral gavage for $12 \mathrm{hr}$, or with CA for $12 \mathrm{hr}$ prior to ethanol for $12 \mathrm{hr}$ (Ethanol + CA). CA concentration in (A) liver and (B) serum of STC2 ${ }^{+/+}$mice were determined using HPLC/MS-MS. * indicates statistically significant difference compared to saline (control) and ethanol only treatment groups. $n$ 
= 3 mice in each group. Quantitative RT-PCR for stc2 and cyp1a1 in total liver RNA is shown for (C) $\mathrm{STC}^{+/+}$and (D) STC2 ${ }^{-/-}$mice treated with acute alcohol $( \pm \mathrm{CA})$. Data are normalized to $18 \mathrm{~s}$ rRNA. ${ }^{*}$ indicates statistically significant difference compared to control group. $n=3$ mice in each group.

Figure 5. CA-mediated cytoprotection against acute ethanol-induced apoptosis and liver injury. (A) Fluorometric caspase 3 activity assays were performed on liver homogenates from $\mathrm{STC}^{+/+}$and $\mathrm{STC2}^{-/-}$mice treated with $6 \mathrm{gm} / \mathrm{kg}$ ethanol gavage and/or $12 \mathrm{mg} / \mathrm{kg}$ i.p. injections of CA. Data are normalized to caspase 3 activity in saline (control) group and shown as mean \pm SD from three independent experiments (three mice per treatment group). ${ }^{*} p<0.05$ difference between ethanol and ethanol $+C A$ treated samples. (B) Liver sections from $\mathrm{STC}^{+/+}$and $\mathrm{STC}^{-/}$mice treated with saline, $C A$, ethanol, and ethanol $+C A$, were subjected to TUNEL staining. DAPI was used to visualize all hepatic nuclei (blue) and TMR-red TUNEL reaction mixture probed apoptotic nuclei (red). (C) Quantitation of TUNEL assays. TUNEL positive nuclei labelled with TMR red are normalized to the percentage of total nuclei labeled by DAPI in 8-10 random fields. Each group contained liver sections from three mice. Data are represented as mean \pm SD (* indicates statistically significant difference between ethanol and ethanol + CA groups). (D) Serum ALT activity assays were performed on all treatment groups ( $n=3$ mice per treatment group). * $p<0.05$ difference between ethanol-treated and ethanol + CA treated samples. 
Figure 6. in vivo transfection of STC2. $40 \mu \mathrm{g}$ of STC2/pLIVE or empty pLIVE plasmids were transfected in vivo into $\mathrm{STC2}^{-/-}$mice livers using commercially available polymer-based in vivo-jet PEI-Gal reagent $(6.4 \mu \mathrm{l})$. Livers were extracted $24 \mathrm{hr}$ after transfections. (A) stc2 mRNA message in the liver was quantitated using qRT-PCR from $\mathrm{STC2}^{-/-}$mice transfected with STC2 or empty vectors. 18s ribosomal RNA was used as a normalization control. Data were examined using paired t-test (Sigma Plot software), $n=6,{ }^{*}$ indicates $p<0.05$. (B) Immunoblotting was performed to detect the expression of STC2 protein from liver homogenates upon in vivo delivery of STC2/pLIVE into STC2 ${ }^{-/}$ mice. A representative blot is shown $(n=3)$. (C) Liver sections from $S T C 2^{-/}$mice transfected in vivo with control pLIVE and STC2/pLIVE plasmid, were fixed with $4 \%$ formaldehyde, permeabilized with $0.2 \%$ Triton $X-100$. Sections were stained with an anti-STC2 primary antibody and an Alexa fluor 488 secondary antibody (green). Axiovert 200 epifluorescence microscope (Zeiss) was used for image acquisition ( $n=3$ mice in each group).

Figure 7. STC2 can protect against ethanol-induced hepatotoxicity. (A) $24 \mathrm{hr}$ after in vivo transfections using pLIVE and STC2/pLIVE vectors into STC2 $2^{-/}$mice, $6 \mathrm{gm} / \mathrm{kg}$ ethanol was administered via oral gavage. Twelve hours after ethanol treatment, livers were extracted, and fluorometric caspase 3 assays were performed. Data are presented as mean \pm SD $\left(n=3,{ }^{*} p<0.05\right.$ significant difference between two ethanol-treated groups). (B) Immunocytochemistry performed on primary hepatocytes isolated from $\mathrm{STC2}^{-/}$mice transfected in vivo with empty pLIVE vector and with STC2/pLIVE for $24 \mathrm{hr}$. Hepatocytes were isolated and then treated with $100 \mathrm{mM}$ ethanol for $24 \mathrm{hr}$, fixed with 
$4 \%$ formaldehyde, permeabilized with $0.2 \%$ Triton X-100, and probed with anti-STC2 antibody (green) and anti-cleaved caspase 3 antibodies as an apoptotic marker (red). DAPI was used to stain nuclei (blue). Axiovert 200 epifluorescence microscope was utilized to capture the images (Zeiss). (C) Serum ALT assays were performed using a fluorometric alanine transaminase activity assay kit (Abcam). * denotes statistically significant difference between two ethanol-treated groups, $\mathrm{p}<0.05, \mathrm{n}=3$ mice in each group. 
A

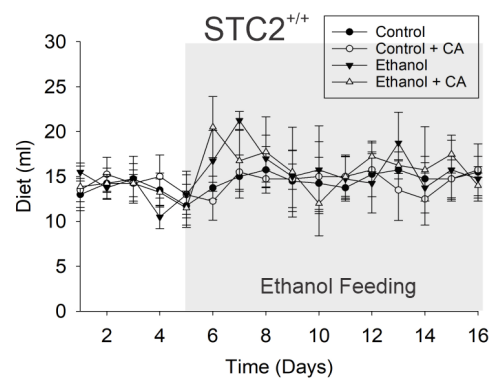

C

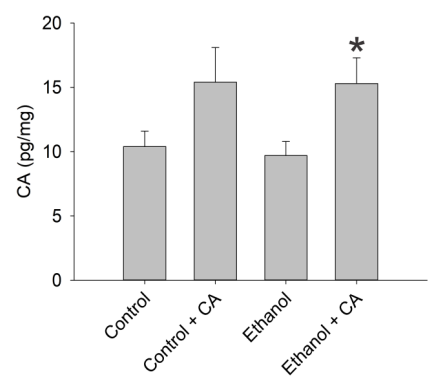

$\mathrm{F}$

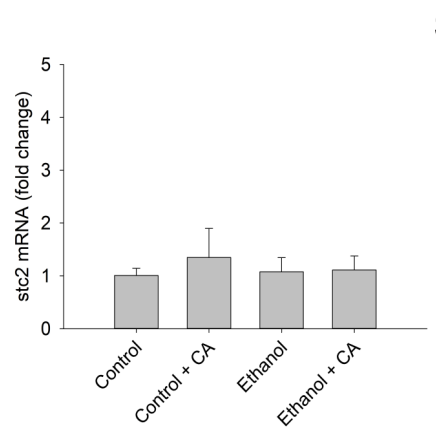

$\mathrm{B}$

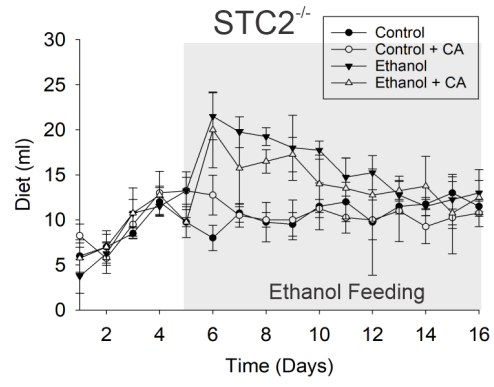

$\mathrm{D}$

$\mathrm{STC}^{+1+}$

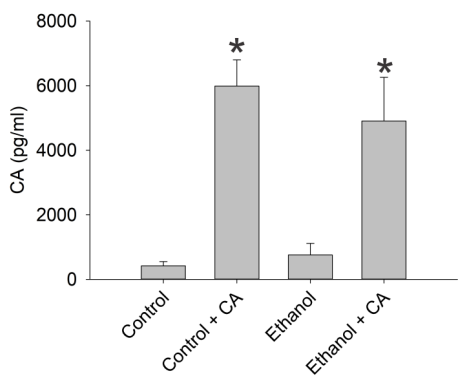

STC2

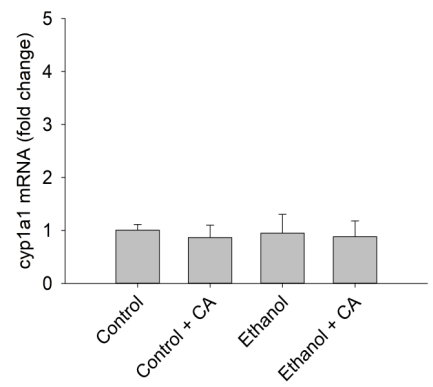

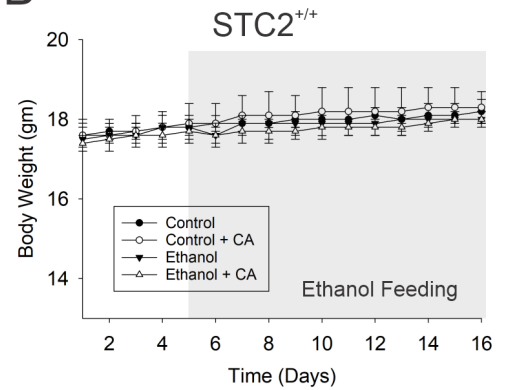

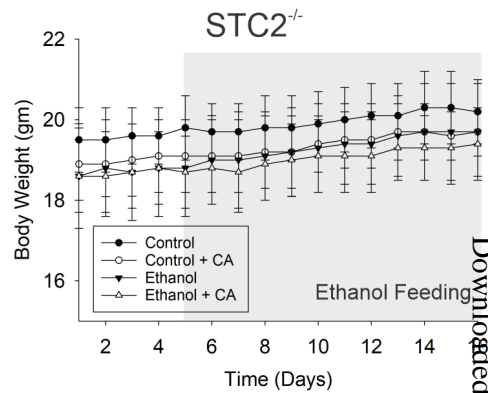

$E$

$\mathrm{STC}^{+/+}$
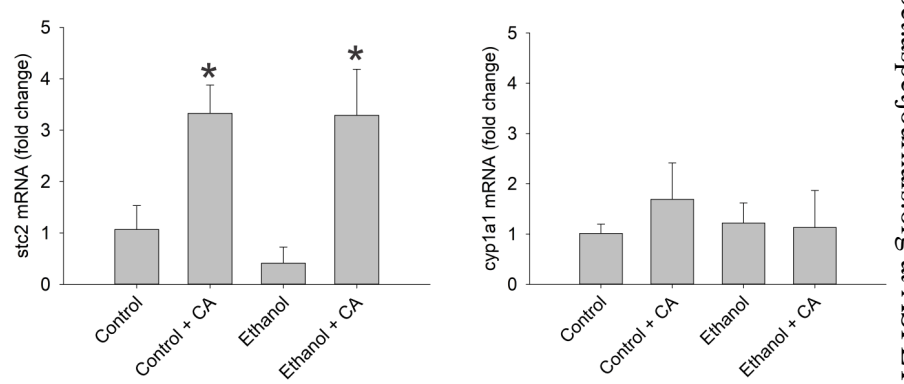

G

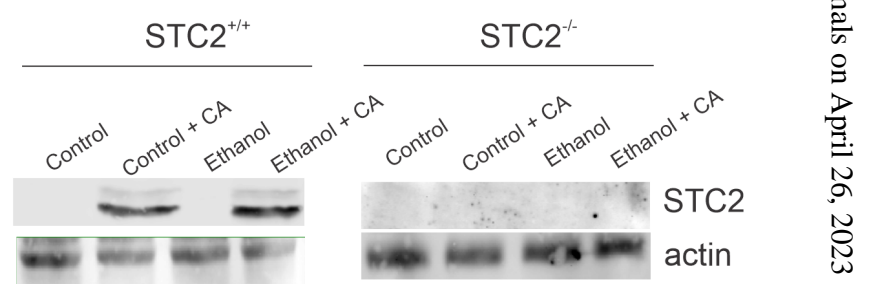


A

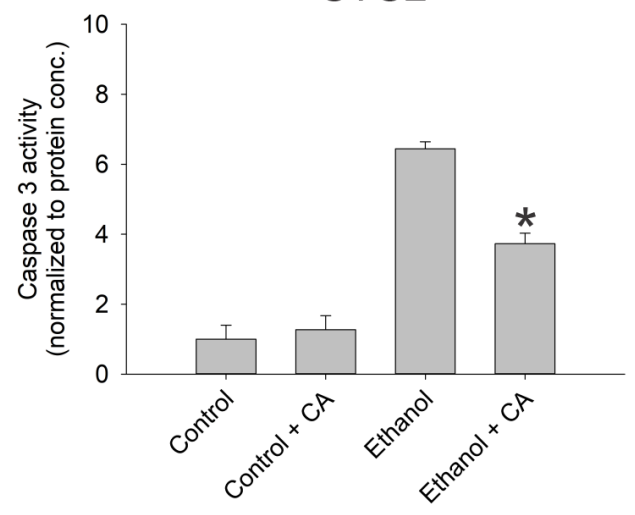

B

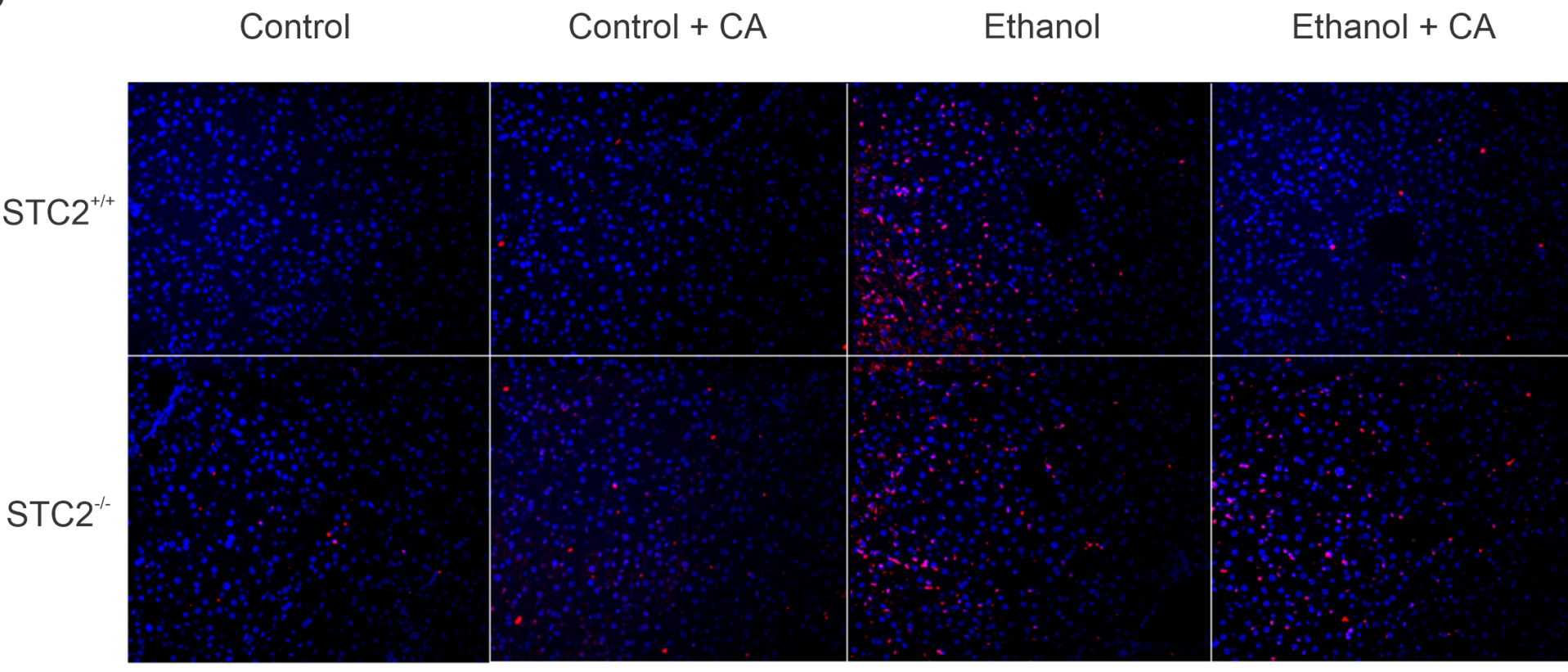

C

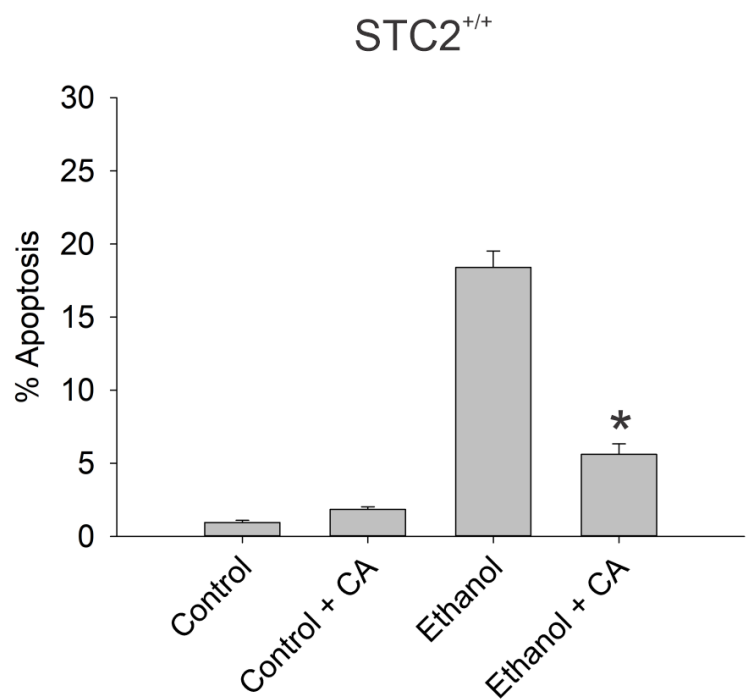

$\mathrm{STC2}^{-/}$

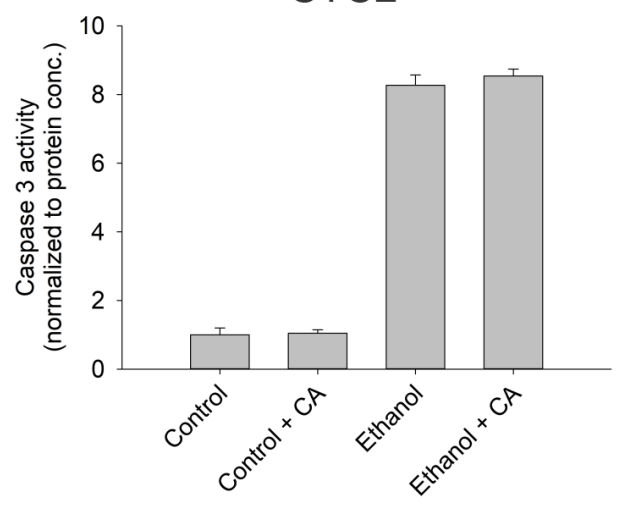

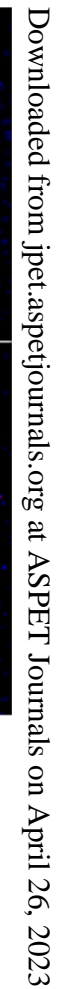

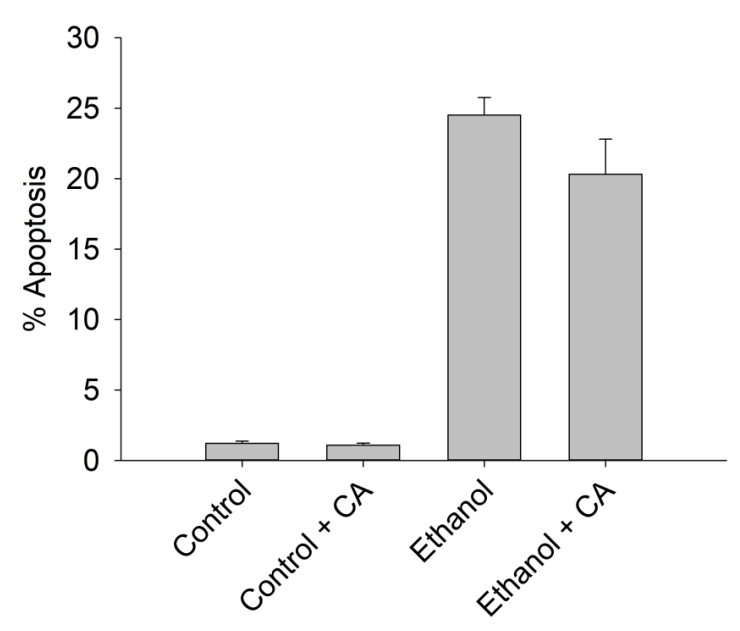


JPET Fast Forward. Published on January 25, 2022 as DOI: 10.1124/jpet.121.000999

A

This article has not been copyedited and formatted. The final version may differ from this version.
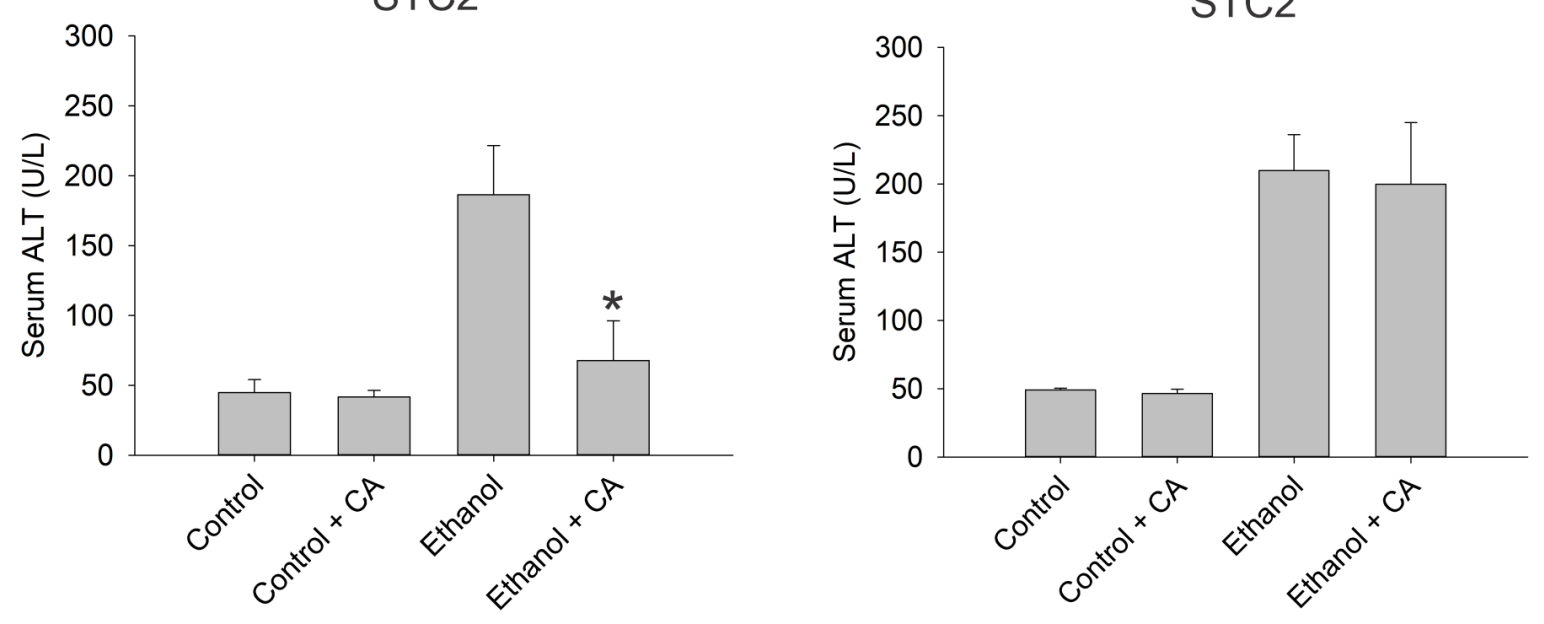

B

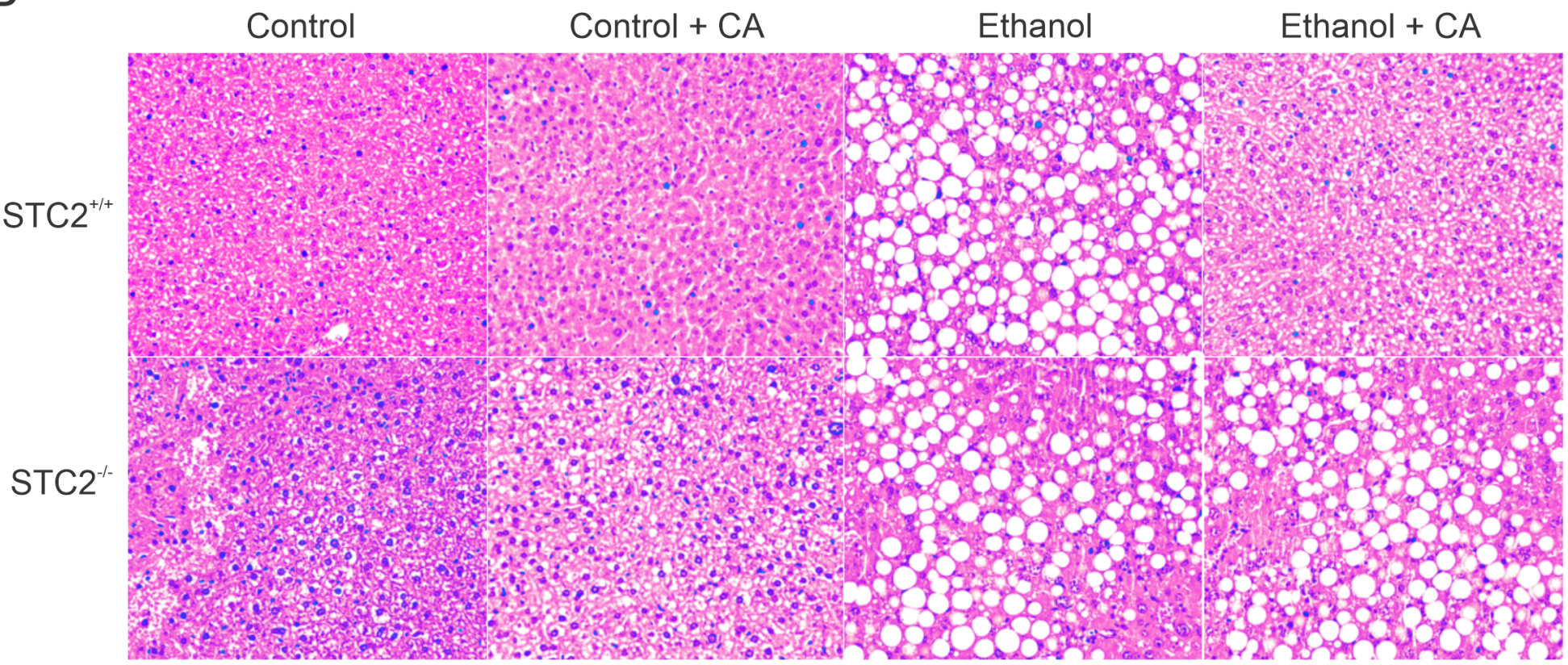

Figure 3 
A This article has not been copyedited and formatted. The final version pax differ from this version.
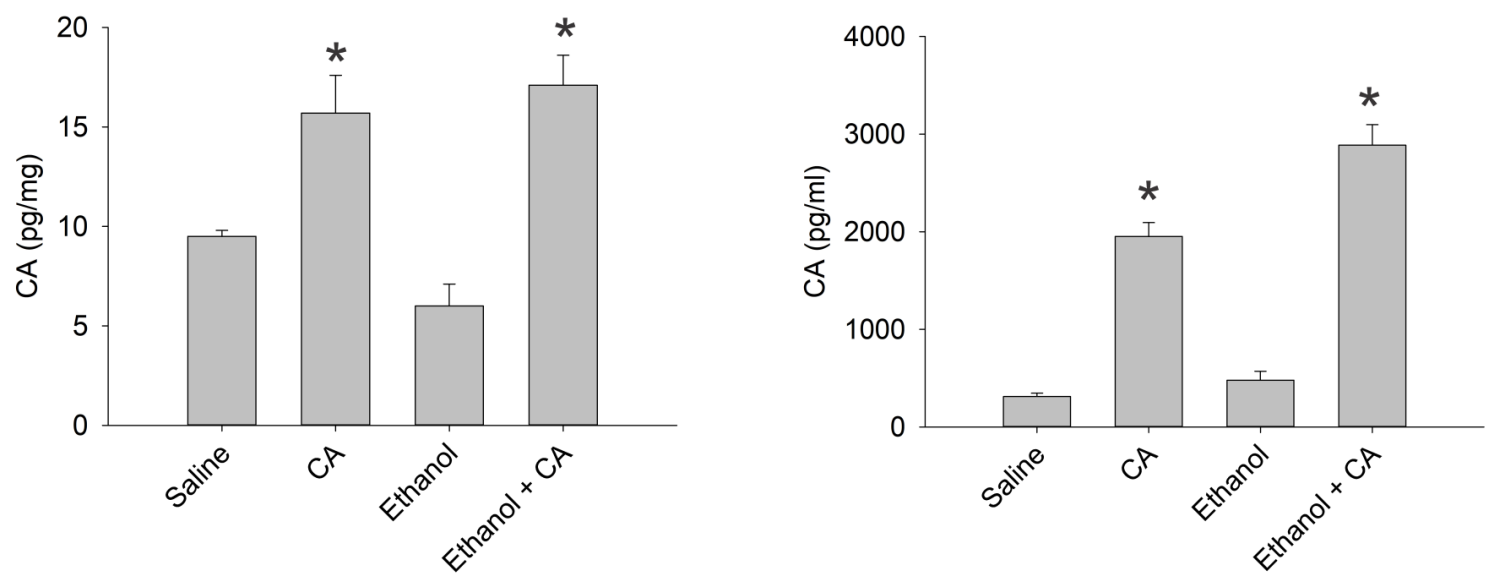

C
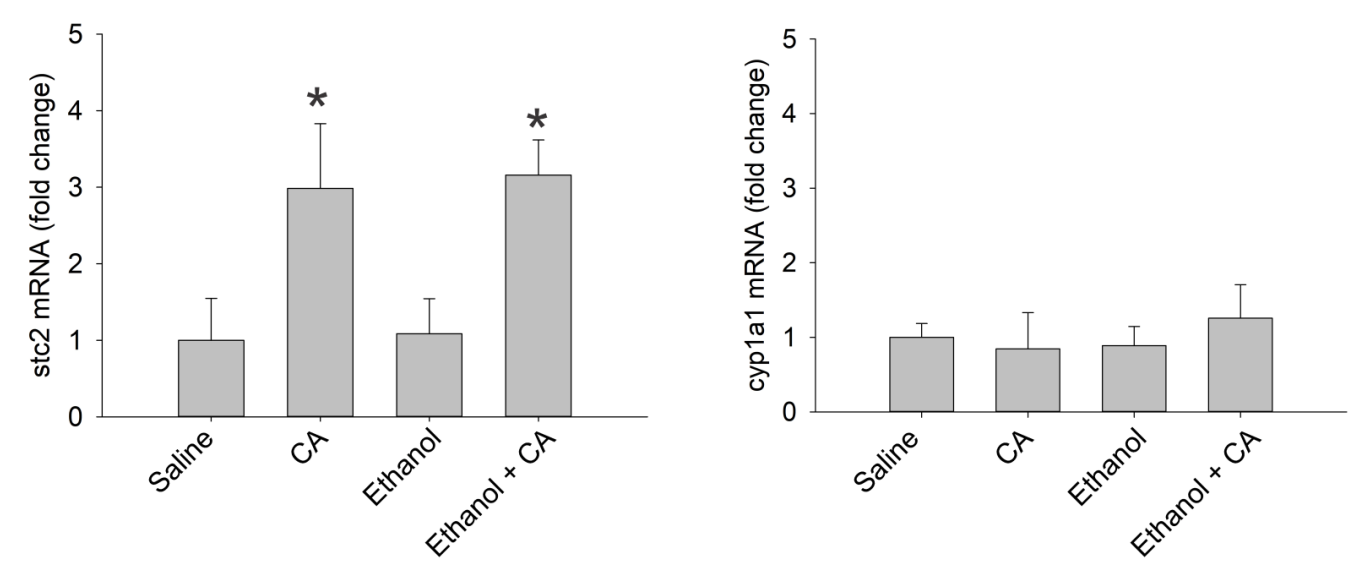

D
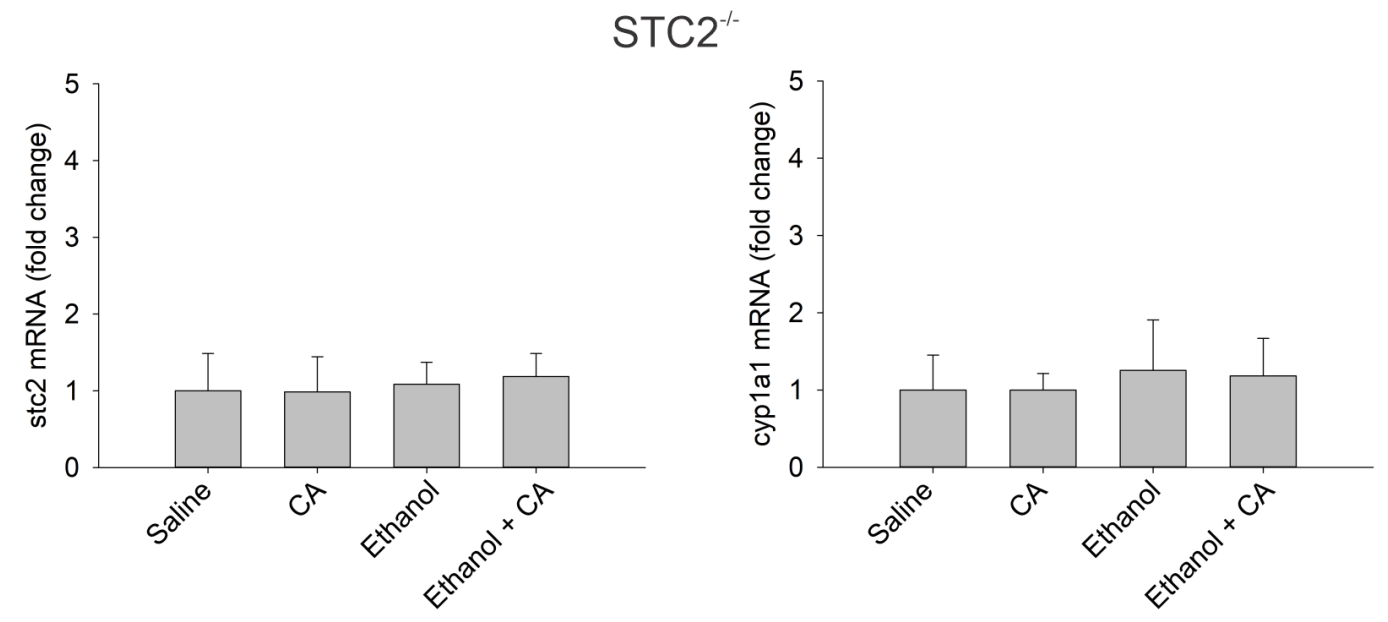
A

$\mathrm{STC}^{+/+}$

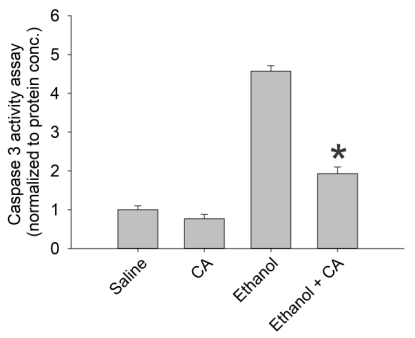

C

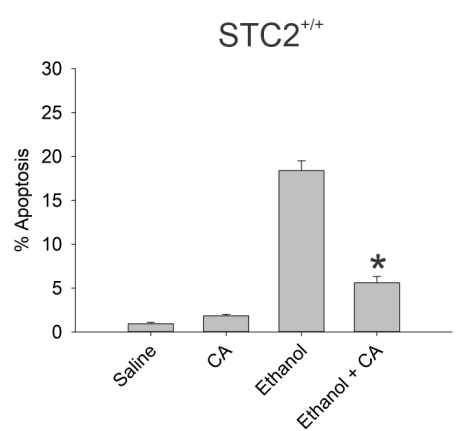

$\mathrm{STC}^{-1}$

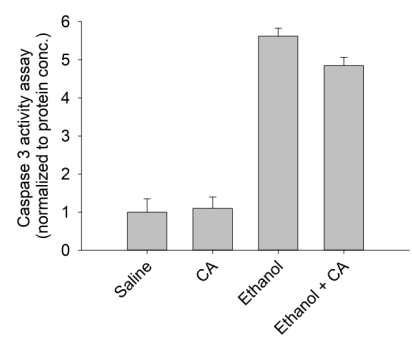

B

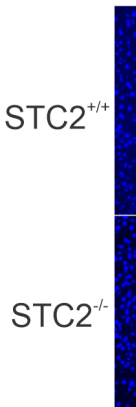

$\mathrm{D}$

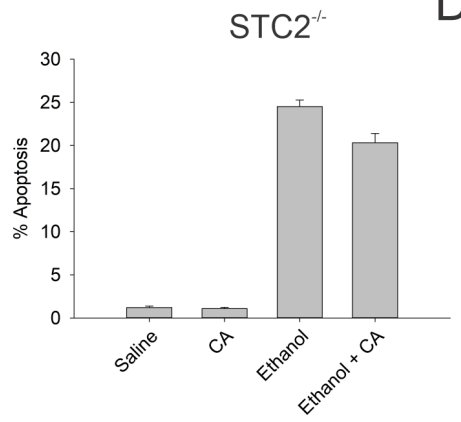

Saline

CA
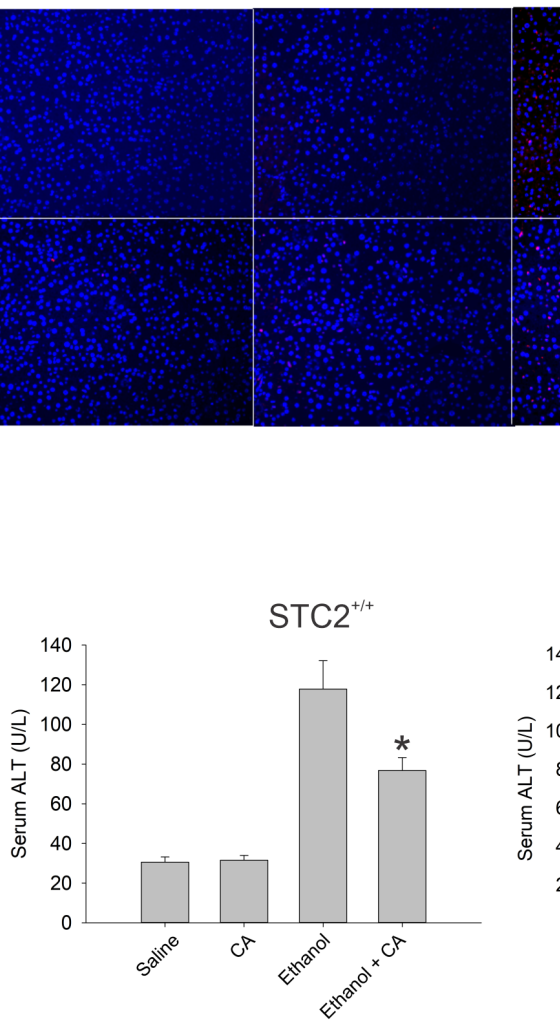

Ethanol

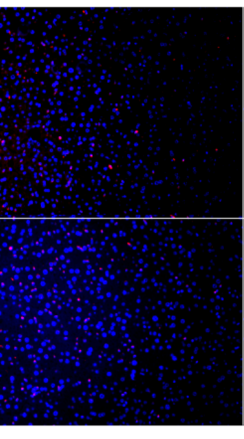

Ethanol $+\mathrm{CA}$
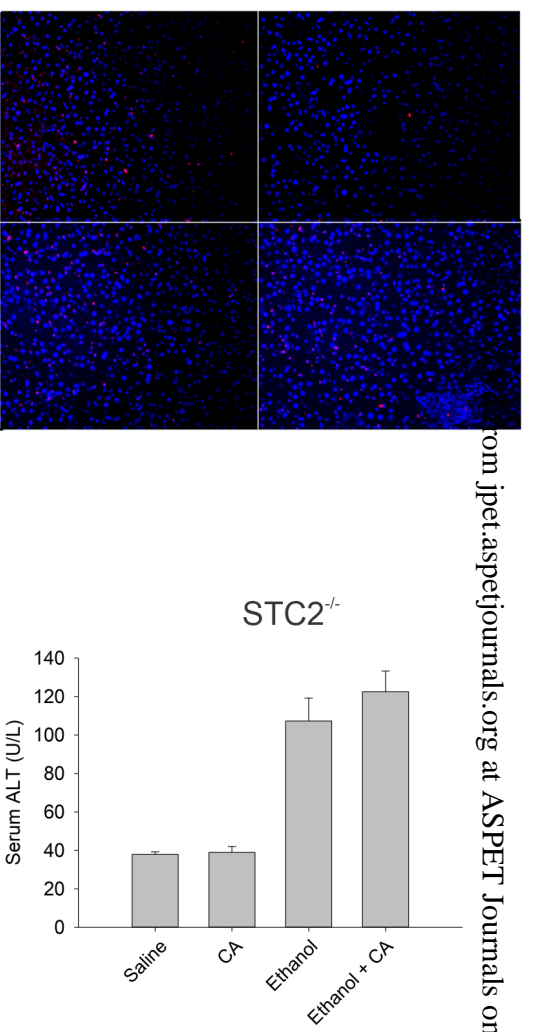

Figure 5 
JPET Fast Forward. Published on January 25, 2022 as DOI: 10.1124/jpet.121.000999

A

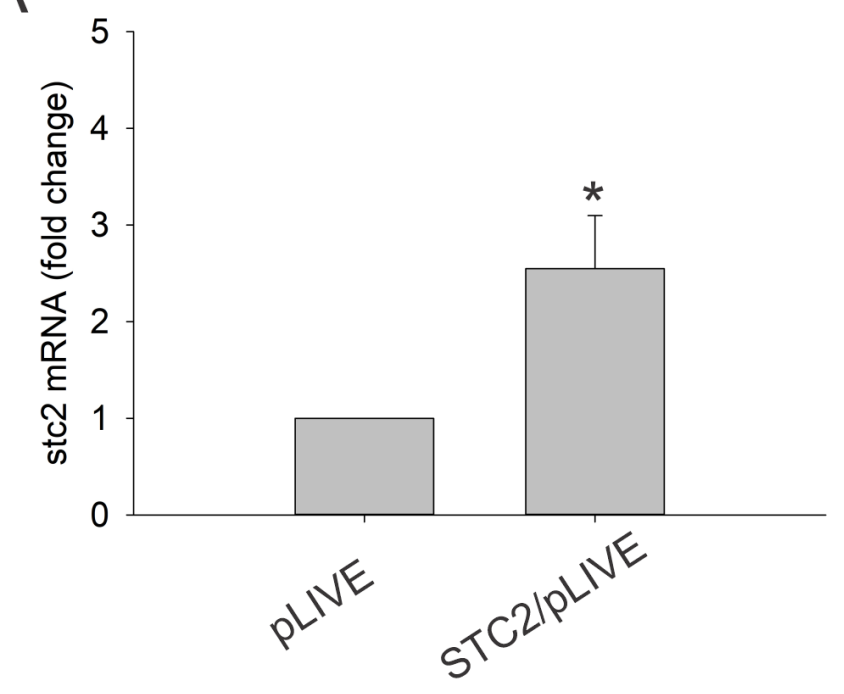

The final version may differ from this version.

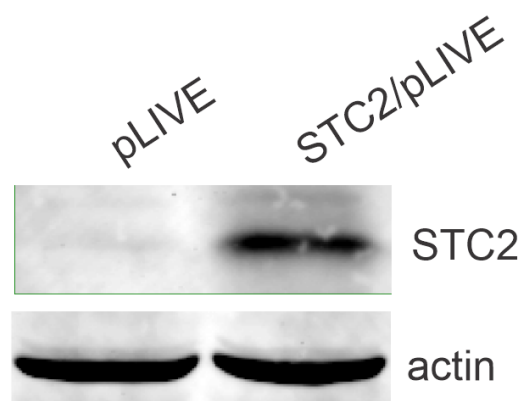

C

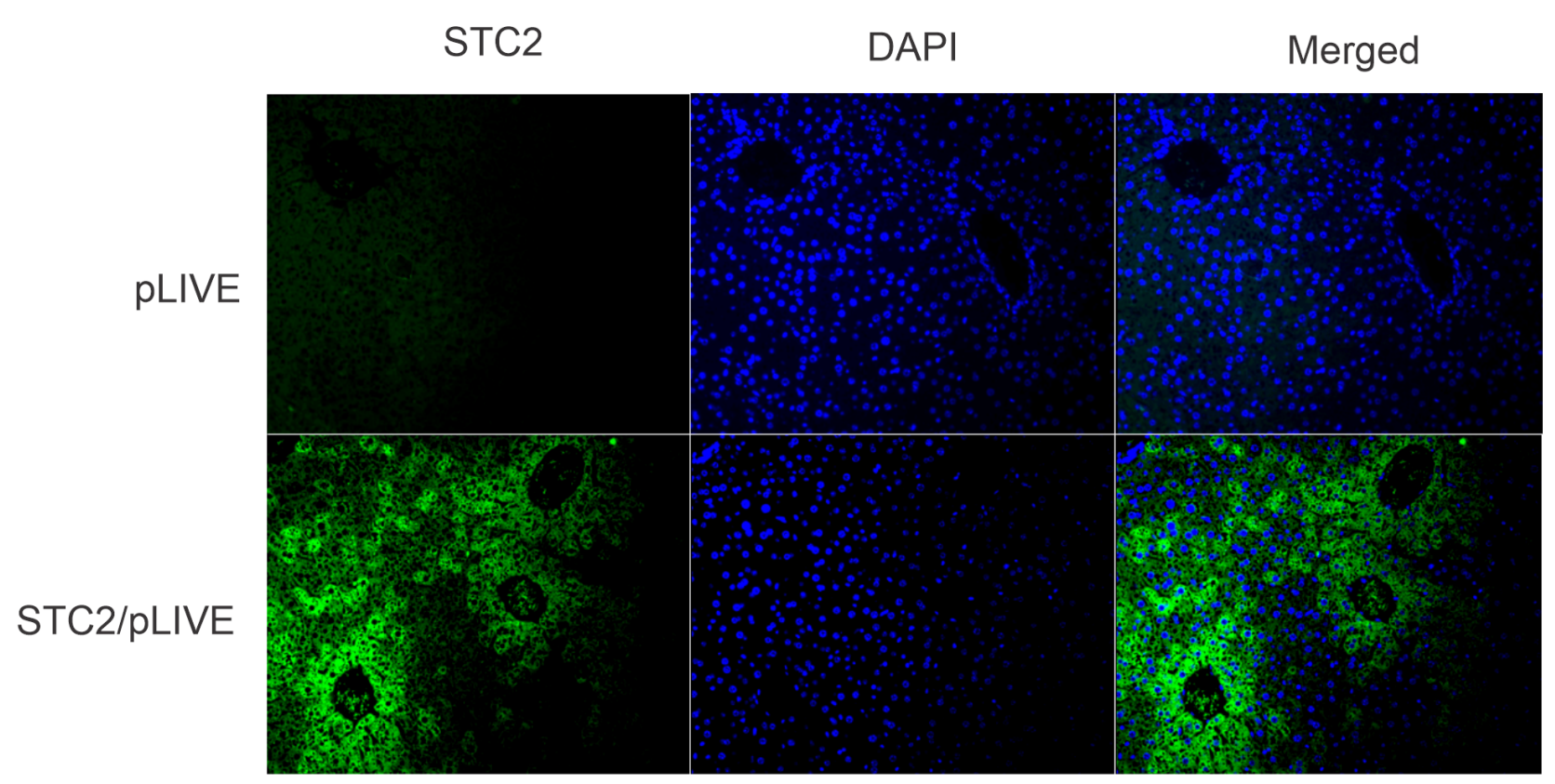


JPET Fast Forward. Published on January 25, 2022 as DOI: 10.1124/jpet.121.000999

A

This article has not been copyedited and formatted. The final version may differ from this version.

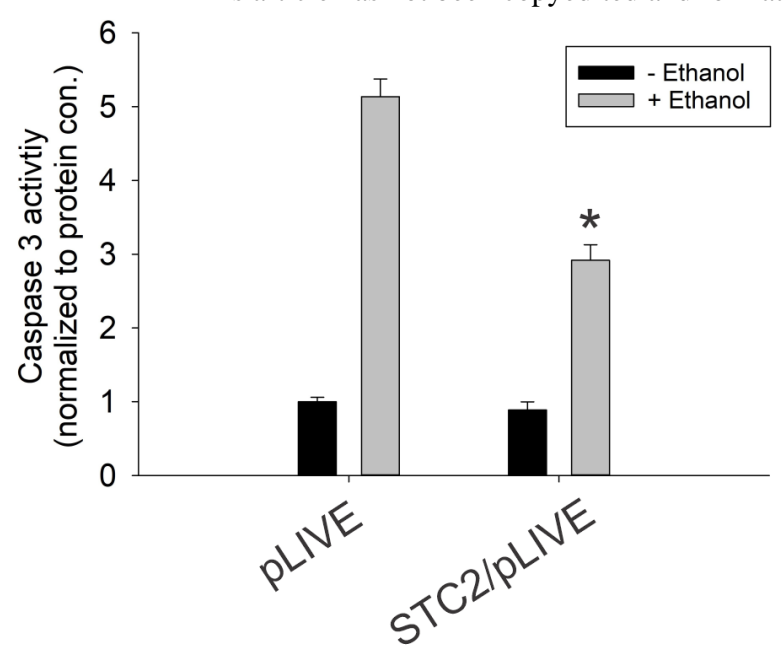

B
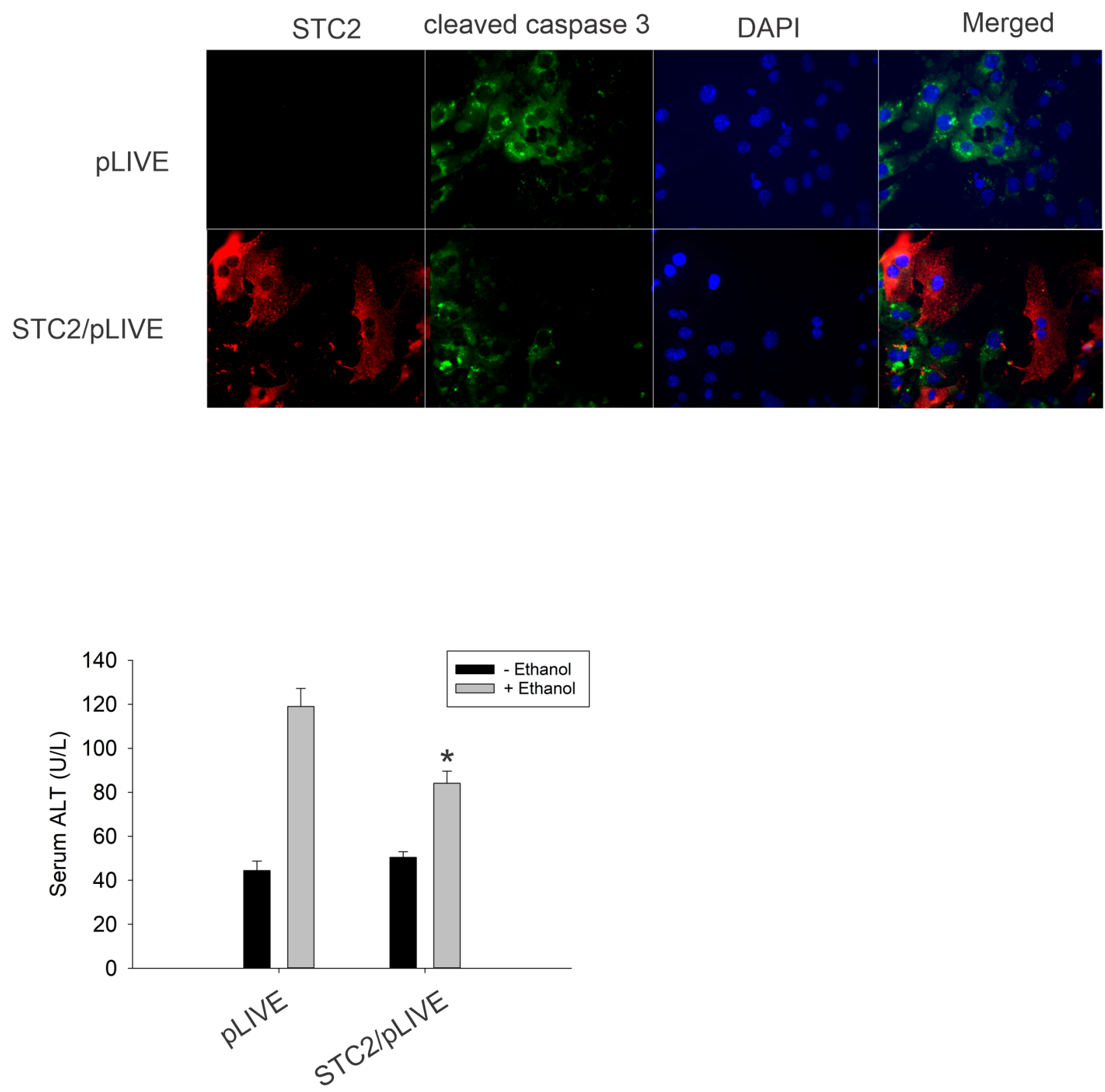